\title{
SARS-CoV-2 sculpts the immune system to induce sustained virus-specific naïve-like and memory B-cell responses
}

\author{
Leire de Campos-Mata ${ }^{1}$ (D), Sonia Tejedor Vaquero', Roser Tachó-Piñot ${ }^{1}$, Janet Piñero ${ }^{2}$, \\ Emilie K Grasset ${ }^{3}$, Itziar Arrieta Aldea ${ }^{4}$, Natalia Rodrigo Melero ${ }^{5}$, Carlo Carolis ${ }^{5}$, Juan P Horcajada ${ }^{4}$, \\ Andrea Cerutti ${ }^{1,3,6}$, Judit Villar-García ${ }^{4}$ \& Giuliana Magri ${ }^{1}$ \\ ${ }^{1}$ Translational Clinical Research Program, Institut Hospital del Mar d'Investigacions Mèdiques (IMIM), Barcelona, Spain \\ ${ }^{2}$ Research Programme on Biomedical Informatics (GRIB), Hospital del Mar Medical Research Institute (IMIM), Department of \\ Experimental and Health Sciences, Pompeu Fabra University (UPF), Barcelona, Spain \\ ${ }^{3}$ Department of Medicine, Immunology Institute, Icahn School of Medicine at Mount Sinai, Mount Sinai, NY, USA \\ ${ }^{4}$ Department of Infectious Diseases, Hospital Del Mar, Institut Hospital del Mar d'Investigacions Mèdiques (IMIM), Barcelona, Spain \\ ${ }^{5}$ Centre for Genomic Regulation (CRG), The Barcelona Institute of Science and Technology, Barcelona, Spain \\ ${ }^{6}$ Catalan Institute for Research and Advanced Studies (ICREA), Barcelona, Spain
}

\section{Correspondence}

G Magri, Translational Clinical Research

Program, Institut Hospital del Mar

d'Investigacions Mèdiques (IMIM),

Barcelona, Spain.

E-mail: gmagri@imim.es

Received 21 May 2021;

Revised 12 August 2021;

Accepted 13 August 2021

doi: $10.1002 /$ cti2.1339

Clinical \& Translational Immunology 2021; 10: e1339

\begin{abstract}
Objectives. SARS-CoV-2 infection induces virus-reactive memory B cells expressing unmutated antibodies, which hints at their emergence from naïve B cells. Yet, the dynamics of virus-specific naïve $B$ cells and their impact on immunity and immunopathology remain unclear. Methods. We longitudinally profiled SARS-CoV-2specific B-cell responses in 25 moderate-to-severe COVID-19 patients by high-dimensional flow cytometry and isotyping and subtyping ELISA. We also explored the relationship of B-cell responses to SARS-CoV-2 with the activation of effector and regulatory cells from the innate or adaptive immune system. Results. We found a virus-specific antibody response with a broad spectrum of classes and subclasses during acute infection, which evolved into an IgG1-dominated response during convalescence. Acute infection was associated with increased mature B-cell progenitors in the circulation and the unexpected expansion of virus-targeting naïve-like B cells. The latter further augmented during convalescence together with virus-specific memory B cells. In addition to a transitory increase in tissue-homing $\mathrm{CXCR}^{+}$ plasmablasts and extrafollicular memory B cells, most COVID-19 patients showed persistent activation of $\mathrm{CD}^{+}$and $\mathrm{CD}^{+} \mathrm{T}$ cells along with transient or long-lasting changes of key innate immune cells. Remarkably, virus-specific antibodies and the frequency of naïve $B$ cells were among the major variables defining distinct immune signatures associated with disease severity and inflammation. Conclusion. Aside from providing new insights into the complexity of the immune response to SARS-CoV2 , our findings indicate that the de novo recruitment of mature Bcell precursors into the periphery may be central to the induction of antiviral immunity.
\end{abstract}


Keywords: adaptive immunity, antibodies, B-cell memory, COVID19 , naïve B cells

\section{INTRODUCTION}

To date, the rapidly spreading severe acute respiratory syndrome coronavirus 2 (SARS-CoV-2) has infected about 200 million people, resulting in more than four million deaths worldwide. ${ }^{1}$ Infection with SARS-CoV-2 causes the coronavirus disease 2019 (COVID-19), which is characterised by a wide variety of clinical manifestations that range from asymptomatic to acute respiratory distress syndrome (ARDS), multiorgan failure and death. ${ }^{2}$ Although such diversity in disease pathogenesis is partially explained by the patient's comorbidities and genetic and sociodemographic factors, severe manifestations of the disease are strongly associated with dysregulated immune responses.,4 Immune dysregulation in severe COVID-19 patients is characterised by delayed and impaired type I interferon responses that associate with failure to control primary infection. ${ }^{5,6}$ The resulting aberrant activation of innate immune cells leads to an exacerbated release of pro-inflammatory cytokines, causing systemic inflammation and tissue damage. ${ }^{7}$ Interestingly, interferon signalling and hyperinflammation may associate with autoimmunity. Indeed, severe COVID-19 patients develop autoantibodies against immunomodulatory proteins, including antibodies against type I interferon. ${ }^{8-10}$

Besides playing a role in immunopathogenesis, the host immune response is a major determinant of recovery and immune protection through the development of durable SARS-CoV-2-specific T- and $B$-cell responses. Several studies have documented the early activation of $\mathrm{CD}^{+}$and $\mathrm{CD}^{+} \mathrm{T}$ cells following SARS-CoV-2 infection and the generation of long-lasting virus-specific T-cell responses required for immune protection. ${ }^{11-14}$ In the early response to SARS-CoV-2, infected individuals generate antibodies against the viral nucleocapsid (NP) and spike (S) proteins. About $90 \%$ of COVID-19 patients produce detectable neutralising antibody responses against the receptor-binding domain (RBD) of the viral S protein, which persist for up to 8 months. ${ }^{15-17}$ Early humoral responses are driven by the transient expansion of antibody-secreting plasmablasts (PBs). During convalescence, humoral memory is sustained by somatically mutated memory switched B cells and long-lived plasma cells. ${ }^{14,16,18,19}$ of note, recent studies identified convergent antibody responses to SARS-CoV-2 by B cells with preferential immunoglobulin heavy chain variable-joining (IGHV-J) gene usage and minimal somatic hypermutation. ${ }^{18,20-25}$ These findings suggest that humoral protection involves SARSCoV-2 recognition by naïve $B$ cells with little or no antigen-driven affinity maturation required. ${ }^{21,26}$

In spite of our growing understanding of SARSCoV-2 infection, both the kinetics and composition of virus-specific B-cell responses remain poorly understood. In particular, the dynamics of virus-reactive naïve $B$ cells and their role in immune protection and immunopathology are unclear. In addition, the temporal trajectories of innate and adaptive immune responses to SARS-CoV-2 and their functional relationship remain elusive. A better understanding of these facets of SARS-CoV-2 infection may help in the evaluation of the protective effects afforded by individual vaccination programmes.

Here, we longitudinally profiled global and virus-specific B-cell responses from a cohort of moderate-to-severe COVID-19 patients at different stages of SARS-CoV-2 infection. We also explored the relationship of B-cell responses to SARS-CoV-2 with the activation of effector and regulatory cells from the innate or adaptive immune system. We identified specific properties of immune response dynamics from COVID-19 patients and unique immune trajectories that associate with disease severity and inflammation. We also found some evidence of a novel mechanism adopted by the host immune system to fight against SARS-CoV- 2 . This mechanism may involve the continuous peripheral recruitment of early mature B-cell precursors to enhance viral recognition by the naïve $\mathrm{B}$-cell repertoire.

\section{RESULTS}

\section{SARS-CoV-2 triggers a broad antibody response in the early stage of infection and a robust and long-lasting RBD-specific IgG1 response}

To dissect the dynamics of humoral immune responses to SARS-CoV-2, we collected blood and 
serum samples from a cohort of 25 hospitalised COVID-19 patients in acute phase of infection (COVT1). Of these patients, $24 \%(n=6$; darker symbols in Figures) were admitted to intensive care unit (ICU). On average, COVT1 samples were collected 11 days post-symptom onset (PSO). A follow-up blood sample was drawn from 20 out of 25 patients (COVT2), including 4 ICU patients, averaging 70 days PSO (Figure 1a). Blood and serum samples were also collected from healthy controls $(n=21)$. Aside from being a major risk factor for fatal outcome in COVID-19 patients, age profoundly influences the immune system of healthy individuals. To minimise these age-related effects, we mostly selected patients younger than 65 (median age $=51$ ) and included age-matched healthy controls (median age $=50$ ). A summary of demographic and clinical data of all the individuals included in this study is provided in Supplementary table 1.

To elucidate whether COVID-19 patients can mount a broad and long-lasting humoral response to SARS-CoV-2, we performed isotype-specific (IgM, $\lg A$ and $\lg G$ ) and subtype-specific (IgA1, $\lg A 2, \lg G 1$, IgG2, IgG3 and IgG4) enzyme-linked immunosorbent assays (ELISAs) that quantified antibody responses to the RBD of the spike protein or NP from SARS-CoV-2. Compared with healthy controls, sera from COVID-19 patients in acute infection (COVT1) and convalescence (COVT2) showed significantly higher titres of all RBD- and NP-specific antibody classes and subclasses analysed (Figure 1b, c). According to our longitudinal study and as previously reported, ${ }^{18,27}$ RBD- and NP-specific $\operatorname{lgM}$ and $\lg A$ titres significantly decreased two months PSO (Figure 1b, c). Interestingly, both IgA1 and $\operatorname{IgA} 2$ subclasses contributed to the decline in virus-specific $\lg A$, suggesting a limited involvement of mucosal immunity during convalescence. Unlike RBD- and NP-specific IgM and IgA, virus-specific IgG titres were maintained over the first two months PSO (Figure 1b, c). Remarkably, RBD-specific IgG1 was the only $\lg G$ subclass that significantly increased over time (Figure 1b).

We further studied the dynamics of the humoral response in COVID-19 throughout the study period by plotting the relative change in antibody levels between COVT1 and COVT2 against the corresponding antibody levels at COVT1. This analysis revealed that the magnitude of relative changes in virus-specific $\lg M$ or IgG titres directly correlated with their initial levels at COVT1. Indeed, patients with initial higher virus- specific IgM or lower IgG titres showed a greater relative decrease or increase, respectively (Figure 1d). This resulted in much less variance in virus-specific IgM or IgG titres among COVT2 samples (Figure 1b, c). Thus, SARS-CoV-2 infection triggers a broad antibody response in terms of antibody classes and subclasses in early stages and an expansion of an RBD-specific and IgG1dominated response during convalescence.

\section{COVID-19 is associated with transitory expansion of circulating plasmablasts and naive $B$ cells during the acute phase of infection}

To further explore the dynamics of the B-cell response to SARS-CoV-2, we analysed circulating $B$ cells from healthy controls and COVID-19 patients in acute infection and convalescence by highdimensional spectral flow cytometry (Supplementary table 2). As reported by others, ${ }^{28}$ the frequency of $\mathrm{CD}_{19^{+}} \mathrm{B}$ cells within live peripheral blood mononuclear cells (PBMCs) was significantly higher in COVT1 than in healthy controls or COVT2 (Figure 2a). T-distributed stochastic neighbour embedding (tSNE) defined the major B-cell populations (Figure 2b), the contribution of each group of samples to these populations (Figure 2c) and the differential expression of multiple surface B-cell proteins within these populations (Supplementary figure 1a). In parallel, we queried the data by traditional gating (Supplementary figures $1 \mathrm{~b}, 2 \mathrm{a}$ and 3a). This analysis revealed that, for most COVID-19 patients, the acute response to SARSCoV-2 was dominated by a transitory expansion of $\mathrm{CD} 38^{++} \mathrm{CD} 10^{-} \mathrm{CD} 27^{\text {high }}$ PBs (Figure $2 \mathrm{~b}-\mathrm{e}$ ), the majority of which expressed HLA-DR ${ }^{+}$(Figure 2f). Next, the analysis of antibody classes and subclasses confirmed the induction of unswitched and $\operatorname{lgA} 1$ or IgG class-switched PBs soon after infection (Figure $2 \mathrm{~g}$ and Supplementary figure $1 \mathrm{c}$ ). We then assessed the homing potential of these PBs through the analysis of CXCR3 and CXCR4 chemokine receptors, which guide PBs to inflamed tissues or bone marrow, respectively. ${ }^{29}$ We found that the majority of PBs from COVT1 had a $\mathrm{CXCR3}^{+} \mathrm{CXCR4}{ }^{-}$phenotype, suggesting their targeted migration into inflamed tissues (Figure $2 \mathrm{~h}, \mathrm{i}$ ). Compared with healthy controls and COVT2, COVT1 samples also showed a significantly increased proportion of $\mathrm{CXCR3}^{+} \mathrm{CXCR4} 4^{+} \mathrm{PBs}$ (Figure 2h, j). 
(a)

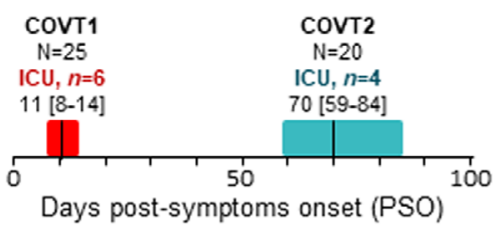

(b)
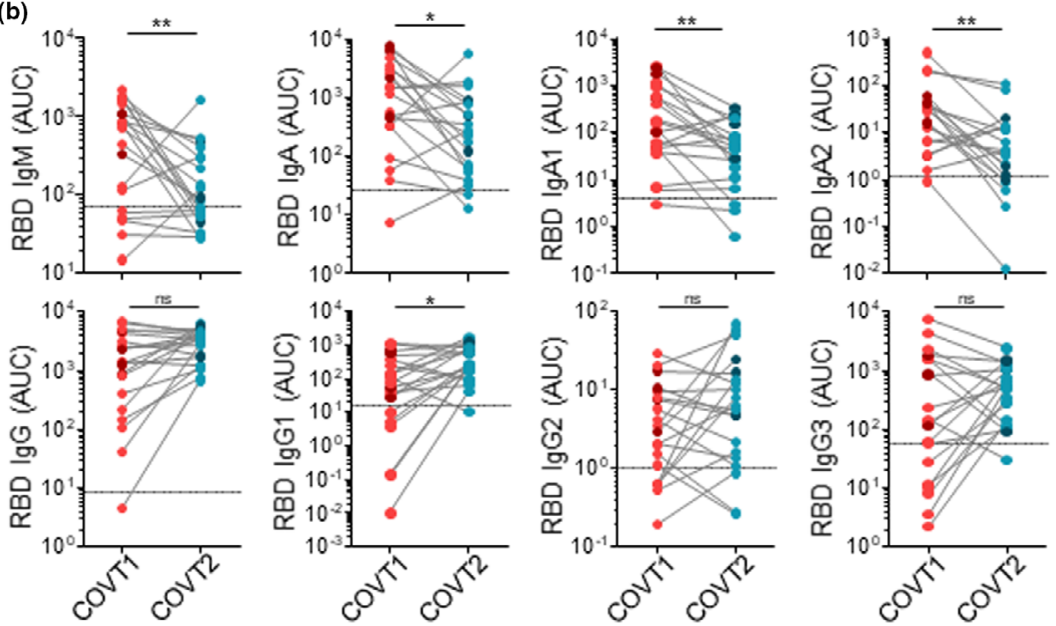

(c)
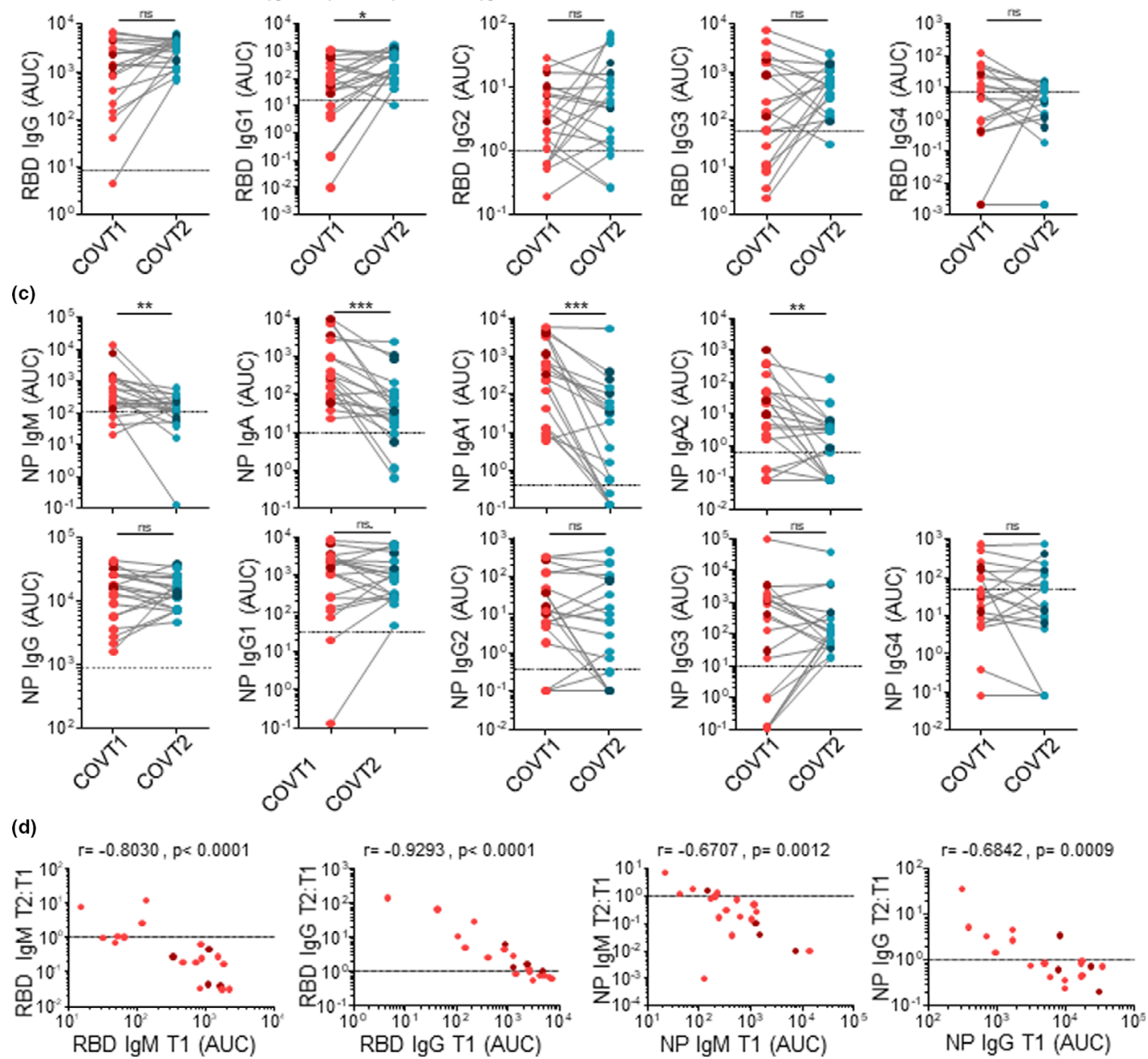

Figure 1. SARS-CoV-2 induces a broad antibody response in the early stage of infection and a long-lasting IgG response. (a) Schematic diagram of the study timeline and cohort characteristics. Range of days post-symptom onset (PSO) is indicated with a box, and median is indicated with a line for COVID-19 patients in the acute (COVT1) and convalescent (COVT2) phase of infection. (b) Area under the curve (AUC) for each of the RBD-specific and (c) NP-specific antibody classes and subclasses analysed from COVT1 and COVT2 sera samples. Sera from healthy controls (HCs) were analysed in parallel to establish negative threshold values defined as the HC AUC mean plus 2 times the standard deviation of the mean. Data are presented as paired individual dots. Dashed line indicates negative threshold. The Wilcoxon matched-pairs test was used to compare COVT1 with COVT2 in b and c. (d) Relative change in antibody levels between COVT1 and COVT2 plotted against the corresponding antibody levels at COVT1. $r$ represents Spearman's rank-order correlation. (a-d) Dark-coloured dots show ICU patients. ns, non-significant $(P>0.05)$, $* P<0.05, * * P<0.01$ and $* * * P<0.001$. COVT1, $n=20 ;$ COVT2, $n=20$. 


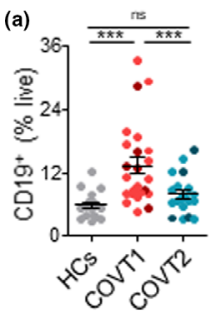

(b)

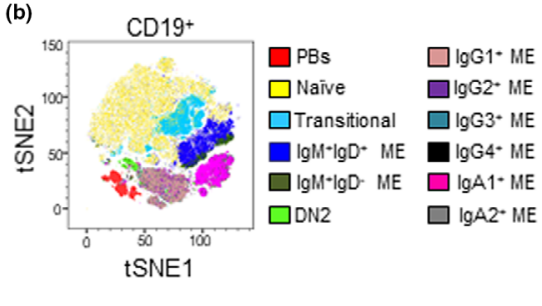

(c)

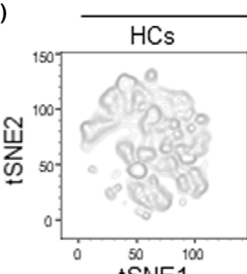

$\mathrm{CD}^{+9^{+}}$
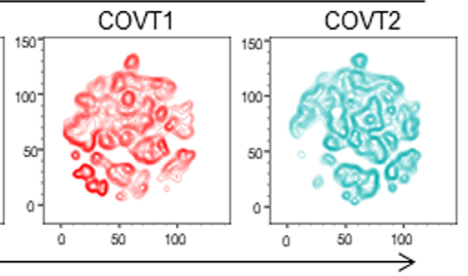

(e)
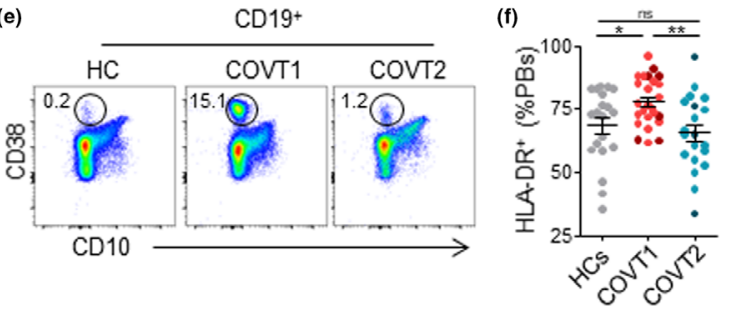

(h)
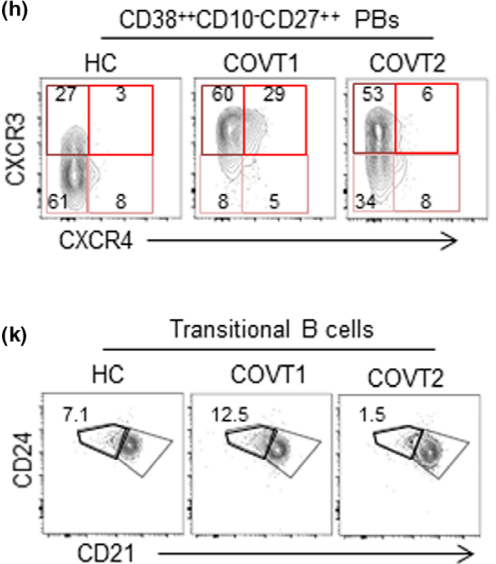

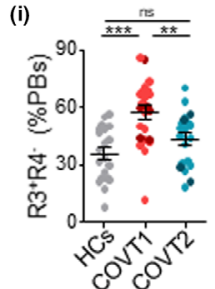

(f)

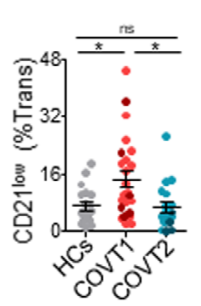

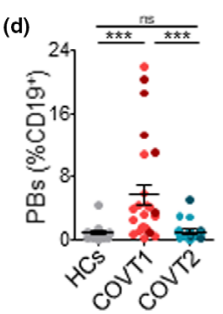
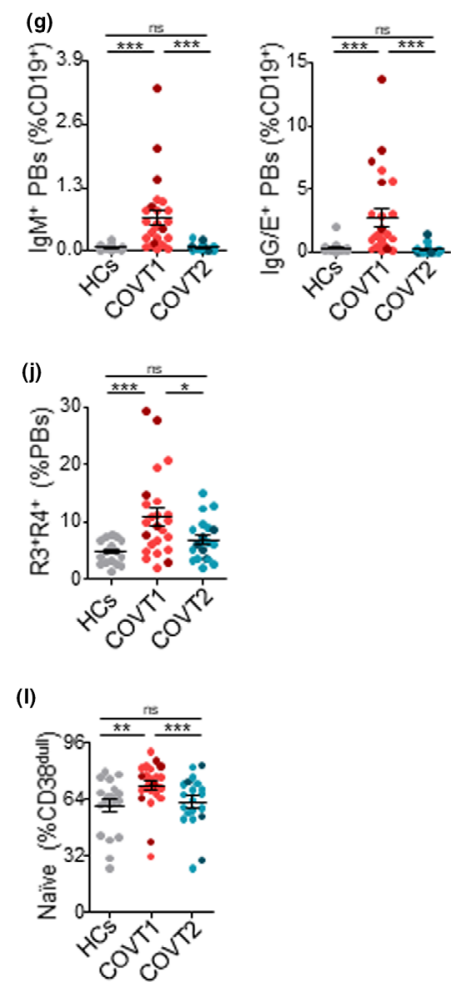

Figure 2. Deep profiling of B-cell subsets in COVID-19 patients reveals transitory expansion of circulating plasmablasts, immature transitional and naive $B$ cells during the acute phase of infection. (a) Frequency of $C D 19^{+} B$ cells from live peripheral blood mononuclear cells (PBMCs) in healthy controls (HCS) and COVT1-COVT2. (b) Merged tSNE projection of CD19+ B cells for HCs $(n=11)$, COVT1 $(n=16)$ and COVT2 $(n=16)$ samples concatenated, with main B-cell populations indicated by colour. PBs, plasmablasts. ME, memory. DN2, CD38 ${ }^{\text {dull }} \mathrm{CD} 10^{-} \operatorname{lgD} \mathrm{CDD}^{-} \mathrm{C} 7^{-} \mathrm{CD} 21^{-} \mathrm{CD} 11 \mathrm{c}^{+}$ double-negative type 2. (c) tSNE projections of $C D 19^{+} B$ cells for each sample group. (d) Frequency of $C D 38^{++} C D 10^{-} \mathrm{CD} 27^{+}$plasmablasts (PBs) from total CD19+ $\mathrm{B}$ cells and (e) representative dot plots in HCs, COVT1 and COVT2. Numbers indicate percentages in the drawn gates. (f) Frequency of HLA-DR ${ }^{+}$from total circulating CD38 ${ }^{++}$CD $10^{-}$CD27 $7^{+}$PBs in HCs, COVT1 and COVT2. (g) Frequencies of IgM ${ }^{+}$PBs (left) and lgG/E ${ }^{+}$PBs (right) from total CD19 ${ }^{+}$B cells. (h) Representative flow cytometric plots of $\mathrm{CXCR3}^{-} \mathrm{CXCR4^{- }}\left(\mathrm{R} 3^{-} \mathrm{R} 4^{-}\right), \mathrm{CXCR3}^{-} \mathrm{CXCR4^{+ }}\left(\mathrm{R3}^{-} \mathrm{R}^{+}\right), \mathrm{CXCR3}^{+} \mathrm{CXCR4^{+ }}\left(\mathrm{R3}^{+} \mathrm{R} 4^{+}\right)$ and $C X C R 3^{+} C X C R 4^{-}\left(R 3^{+} R 4^{-}\right)$PBs. Numbers indicate percentages in the drawn gates. (i) Frequency of $C X C R 3^{+} C X C R 4^{-}$cells within total circulating PBs. (j) Frequency of $\mathrm{CXCR3}^{+} \mathrm{CXCR4^{+ }}$ cells within total circulating PBs. (k) Representative flow cytometric plots (left) and frequency (right) of immature cells $\left(\mathrm{CD} 38^{\text {int }} \mathrm{CD} 10^{+} \mathrm{IgD}{ }^{+} \mathrm{CD} 27^{-} \mathrm{CD} 21^{\text {low }}\right)$ from total transitional B cells, gated with thick black line. Numbers indicate percentages in the drawn gates. (I) Frequency of naive $B$ cells $\left(C D 19^{+} C D 38^{\text {int }} C D 27^{-} \operatorname{lgD}{ }^{+}\right)$from $C D 19^{+} C D 38^{\text {dull }} B$ cells in each group of samples. Data are presented as individual dots. Bars represent mean \pm standard error mean (SEM). Dark-coloured dots show ICU patients. The two-tailed Mann-Whitney U-test was performed to compare HCs with COVT1 and HCs with COVT2. The Wilcoxon matched-pairs test was performed to compare COVT1 with COVT2. ns, non-significant $(P>0.05), * P<0.05, * * P<0.01$ and $* * * P<0.001$. Unless mentioned otherwise, HCs, $n=19 ;$ COVT1, $n=25 ;$ COVT2, $n=20$. 
The tSNE projections also highlighted prominent differences in the transitional and naïve B-cell compartments among healthy controls, COVT1 and COVT2 (Figure 2b, $c$ and Supplementary figure 1a). Using conventional gating strategies (Supplementary figure 2a) and pairwise longitudinal comparisons, we identified an increased proportion of immature $C D 21^{\text {low }}$ transitional $B$ cells (Figure 2k) and a highly significant transient expansion of naïve $B$ cells during the acute phase of infection (Figure 2l). Furthermore, our data revealed a positive correlation between the frequency of naïve $B$ cells and the frequency of $\mathrm{CD}_{19}{ }^{+} \quad \mathrm{B}$ cells (Supplementary figure 2b), which implies that naive B-cell expansion could account for the increased frequency of $\mathrm{CD}_{19^{+}} \mathrm{B}$ cells. These changes likely reflect an increased inflammationdependent mobilisation of developing $B$ cells from the bone marrow into the periphery, a phenomenon also observed in other infections. ${ }^{30}$ Moreover, compared with similar cells from healthy controls, naïve B cells from COVT1 exhibited significantly lower expression of CD21, HLA-DR, IgD and the chemokine receptors CCR6, CXCR5 and CXCR3 but not CCR7 (Supplementary figure $2 \mathrm{c}-\mathrm{i})$. Thus, aside from promoting a transient induction of $\mathrm{CXCR3}^{+}$unswitched and class-switched PBs, infection-associated inflammation may induce the mobilisation of precursors of mature $B$ cells together with the transient expansion of naïve $B$ cells with an atypical phenotype.

\section{SARS-CoV-2 infection drives transient increase in extrafollicular memory switched $B$ cells and long-lasting expansion of IgG1 memory B cells}

To gain insight into the dynamics of B-cell memory (ME) responses to SARS-CoV-2, we analysed the frequency of different antigenexperienced B-cell populations. First, we found that the frequency of $M E B$ cells within total CD19 ${ }^{+}$B cells was significantly lower in acute COVT1 than in COVT2 and healthy controls (Supplementary figure $3 a$ and Figure 3a), presumably because of the transient expansion of newly formed PBs and naïve B cells. Unlike PBs but similar to naïve $B$ cells, the frequency of $\mathrm{CXCR3}^{+} \mathrm{ME} \mathrm{B}$ cells diminished during the acute phase of infection (Figure 3b), suggesting a possible impairment in their recruitment into inflamed tissues and lymphoid follicles. ${ }^{31}$ Within the ME B-cell compartment, we observed a significant and persistent reduction in the proportion of $\operatorname{lgM}^{+} \lg D^{+} \mathrm{CD} 27^{+}$unswitched ME B cells in COVID-19 patients (Figure 3c) and a progressive expansion of IgG1-expressing ME B cells (Figure 3d). Interestingly, the frequency of unswitched ME B cells positively correlated with the serum concentration of inflammatory marker ferritin (Figure 3e) and with NP-specific IgM titres (Figure 3f). Moreover, COVID-19 patients with higher plasma concentration of ferritin and other markers of inflammation (data not shown) also showed a lower frequency of IgG1 ME B cells during acute infection (Figure 3g). Remarkably, ME B cells expressing other IgG subclasses did not increase after infection (Supplementary figure $3 b$ ). These results may reflect the consolidation of efficient antiviral IgG1-mediated immunity in less severe patients.

In agreement with findings published previously, ${ }^{32}$ we categorised $\operatorname{lgD}{ }^{-} \mathrm{CD} 27^{-}$doublenegative (DN) ME $B$ cells as early activated $\mathrm{CD} 27^{-} \mathrm{CD} 21^{+} \mathrm{CD} 11 \mathrm{c}^{-}$ME or DN1, extrafollicular $\mathrm{CD} 27^{-} \mathrm{CD} 21^{-} \mathrm{CD} 11 \mathrm{C}^{+} \mathrm{PB}$ precursors or $\mathrm{DN2}$, and DN3 CD27 ${ }^{-} \mathrm{CD} 21^{-} \mathrm{CD} 11 \mathrm{C}^{-} \mathrm{B}$ cells (Supplementary figure $3 c$ ). The analysis of these ME B-cell subsets revealed a significant and transient increase in the frequency of $\mathrm{CD}^{-} 7^{-} \mathrm{IgD}{ }^{-}$DN cells in COVT1 compared with COVT2 and healthy controls (Figure 3h), as reported by others. ${ }^{28}$ Among DN B cells, DN2 cells are recognised as primed precursors of antibody-secreting cells that differentiate from newly activated naïve B cells through an extrafollicular pathway. In contrast, DN3 has unknown origin and function. ${ }^{28}$ First, we quantified the frequency of DN2 cells within different ME B-cell subsets distinguished on the basis of their expressed isotype or subclass. We found a significantly increased proportion of DN2 in $M E$ B cells expressing $\lg G 3, \lg G 1$ and, to a lesser extent, IgA1 (Supplementary figure $3 \mathrm{~d}$ ). The frequencies of extrafollicular ME DN2 B cells and DN3 cells were higher in COVT1 than in COVT2 and healthy controls (Figure 3i, j). Interestingly, the most significant increase in DN2 was observed within the $\operatorname{lgG} 1^{+} \mathrm{ME}$ B-cell subset (Figure 3k). Thus, SARS-CoV-2 infection induces the transient expansion of extrafollicular $\operatorname{lgG} 1^{+} \mathrm{ME} B$ cells, which is followed by a long-lasting $\lg \mathrm{G}^{+} \mathrm{ME}$ Bcell response. 


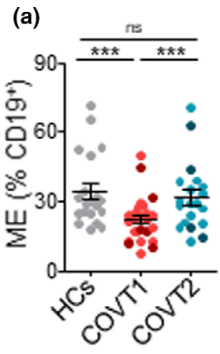

(d)

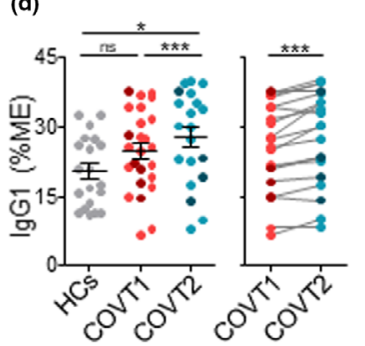

(g)

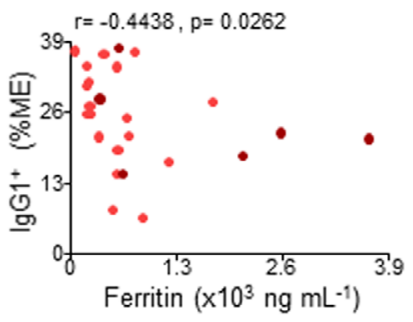

(i)

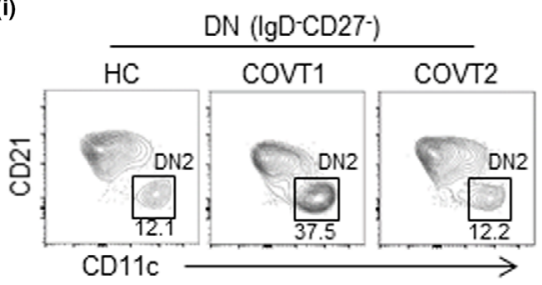

(b)

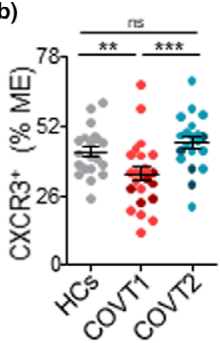

(h)

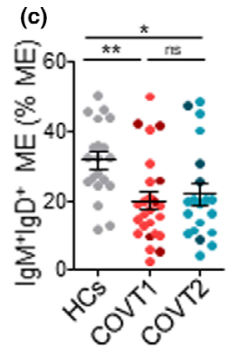

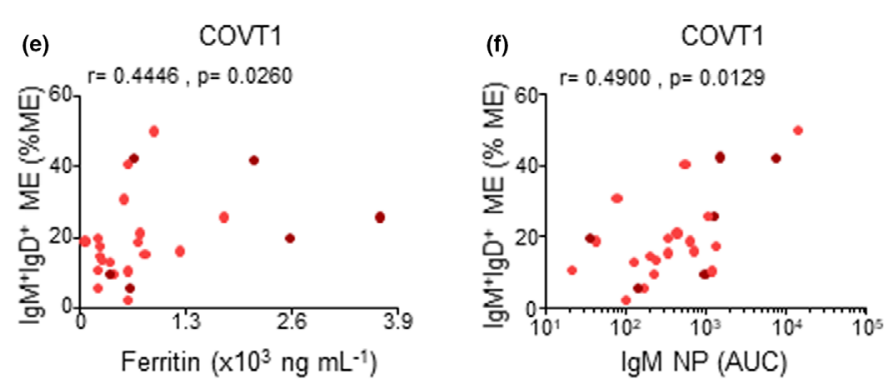
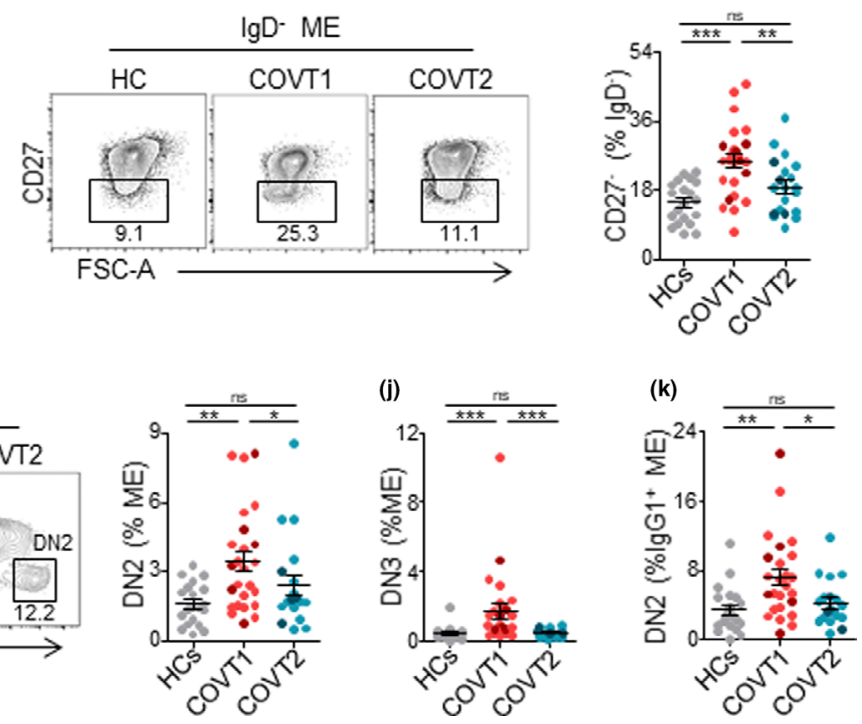

Figure 3. COVID-19 is associated with temporary expansion of extrafollicular switched memory B cells, long-lasting contraction of $\operatorname{lgM}^{+} \operatorname{lgD}{ }^{+} C D 27^{+}$memory $B$ cells and late increase in $\operatorname{lgG} 1^{+}$memory $B$ cells. (a) Frequency of memory (ME) $B$ cells defined as depicted in Supplementary figure 3 from total CD19 $B$ cells in HCs, COVT1 and COVT2. (b) Frequency of CXCR3 ${ }^{+}$cells from total ME B cells in HCs, COVT1 and COVT2. (c) Frequency of $C D 38^{\text {dull }} C D 10^{-} \operatorname{lgM} M^{+} \lg D^{+} C D 27^{+} \mathrm{ME} \mathrm{B}$ cells within total ME B cells in HCs, COVT1 and COVT2. (d) Frequency of $\operatorname{lgG} 1^{+}$ME B cells within total ME B cells in HCs, COVT1 and COVT2 (left) and paired analysis in COVT1 $(n=20)$ and COVT2 ( $n=20$, right). (e) Spearman's correlation analysis of ferritin levels in COVT1 plotted against $C D 38^{\text {dull }} C D 10^{-} \operatorname{lgM}^{+} \operatorname{lgD}{ }^{+} C D 27^{+} M E$ cells within total ME $B$ cells in COVT1. (f) Spearman's correlation analysis of NP-specific IgM antibody titres in COVT1 plotted against CD $38^{\text {dull }} C D 10^{-} \operatorname{lgM}{ }^{+} \operatorname{lgD} D^{+} C D 27^{+} M E B$ cells within total ME B cells in COVT1. (g) Spearman's correlation analysis of IgG1 ME B cells within total ME B cells in COVT1 plotted against ferritin levels in COVT1. (e-g) $r$ represents Spearman's rank-order correlation. (h) Representative flow cytometric plots and frequency of DN memory B cells defined as $C D 38^{\text {dull }} \mathrm{CD} 10^{-} \mathrm{IgD} \mathrm{D}^{-} \mathrm{CD} 27^{-}$out of total $\operatorname{Ig} \mathrm{D}^{-} \mathrm{ME} B$ cells. Numbers indicate percentages in the drawn gates. (i) Representative flow cytometric plots and frequency of extrafollicular DN2 ME B cells defined as CD38 $8^{\text {dull }} C D 10^{-} \operatorname{lgD}{ }^{-} C D 27^{-} C D 21^{-} C D 11 c^{+}$out of total ME $B$ cells. Numbers indicate percentages in the drawn gates. (j) Frequency of DN3 ME B cells defined as CD38 ${ }^{\text {dull }} C D 10^{-} \operatorname{lgD}{ }^{-} C D 27^{-} C D 21^{-} C D 11 c^{-}$out of total ME B cells. (k) Frequency of DN2 ME B cells from total $\operatorname{lgG} 1^{+}$ME B cells. Data are presented as individual dots. Dark-coloured dots show ICU patients. Error bars represent mean \pm SEM. The two-tailed Mann-Whitney U-test was performed to compare HCs with COVT1 and HCs with COVT2. The Wilcoxon matched-pairs test was performed to compare COVT1 with COVT2. ns, non-significant $(P>0.05), * P<0.05, * * P<0.01$ and $* * * P<0.001$. Unless mentioned otherwise, HCS, $n=19 ;$ COVT1, $n=25 ;$ COVT2, $n=20$. 


\section{SARS-CoV-2 induces RBD-specific PBs during acute infection followed by sustained expansion of circulating RBD-specific naïve and memory switched $B$ cells in convalescence}

Next, a fluorescently labelled recombinant RBD probe was used to identify SARS-CoV-2-specific B cells capable of producing potentially neutralising antibodies (Supplementary figure 4a). We confirmed the specificity of our assay by comparing our results with those obtained using a double discrimination strategy via the inclusion of two fluorescently labelled RBD probes (Supplementary figure 4b). Antigen-binding $\mathrm{CD}_{19}{ }^{+} \mathrm{B}$ cells were further characterised according to the expression of CD27, CD21, CD11C, HLA-DR, IgM, IgD, IgA and the Ig light chain $\lambda$ (Supplementary figure $4 c$ and Supplementary table 3). In agreement with published studies, ${ }^{14,16,17}$ SARS-CoV-2 infection induced a rapid increase in the frequency of RBDspecific $\mathrm{CD}_{19}^{+}$B cells at COVT1 that persisted 2 months after viral exposure (Figure 4a). Interestingly, the phenotypic characterisation of these antigen-binding $B$ cells revealed significant changes in virus-specific B-cell populations when the acute phase was compared to the convalescent phase of infection (Figure $4 \mathrm{~b}$ and Supplementary figure 4d). Consistent with the observed expansion of PBs, COVT1 showed an increased frequency of RBD-specific $\mathrm{CD} 27^{\text {high }} \mathrm{CD} 21^{-}$PBs compared with healthy controls and COVT2 (Figure $4 \mathrm{c}$ and data not shown). Remarkably, virtually $100 \%$ of them expressed HLA-DR (Figure 4d).

In addition, RBD-targeting $\operatorname{lgM}^{+} \lg { }^{+} \mathrm{CD} 27^{-}$ naïve $B$ cells increased progressively in COVID-19 patients (Figure 4e). These cells were enriched in CD11 $\mathrm{C}^{+}$early activated $\mathrm{B}$ cells in COVT1 and even more in COVT2 (Figure 4f, g). Of note, the frequency of RBD-specific naive $B$ cells during convalescence strongly correlated with the frequency of total naive $B$ cells in the acute phase of infection (Figure 4h), suggesting that the early mobilisation of developing $B$ cells to the periphery and the expansion of naïve $B$ cells could contribute to humoral defence by increasing germline RBD-specific B cells. To elucidate the mechanisms leading to the sustained enrichment of RBD-targeting naïve $B$ cells, we measured the plasma concentration of IL-7, a cytokine involved in $\mathrm{B}$ and $\mathrm{T}$ lymphopoiesis. ${ }^{33}$ Compared with healthy controls, COVID-19 patients showed more IL-7 during acute infection (Supplementary figure $4 \mathrm{e}$ ) and its concentration correlated with the frequency of RBD-specific naïve $B$ cells in COVT2 (Supplementary figure 4f). Additionally, RBD-specific naïve $B$ cells expressed more $\lg \lambda$ than total naive $B$ cells (Figure $4 \mathrm{i}$ ). Given that $\lg \lambda$ light chain has a more varied structural repertoire than $\lg \kappa_{,}{ }^{34} \lg \lambda$ enrichment may provide the host with the advantage of developing a broader humoral response to SARS-CoV-2.

We then analysed whether RBD-specific ME B cells were induced and maintained throughout the study's time course. The number of RBD ${ }^{+} \mathrm{ME} B$ cells in COVT1 was significantly greater than in healthy controls and increased even further in COVT2 (Figure 4j). Similarly, there was a sustained increase in the number of RBD-specific $\lg G\left(\operatorname{lgM}^{-} \lg D^{-} \lg A^{-}\right)$ class-switched ME and, to a lesser extent, in RBDspecific $\operatorname{lgM}^{+} \operatorname{IgD}^{+} \mathrm{CD} 27^{+}$unswitched $\mathrm{ME} B$ cells (Figure 4k, I). The RBD-specific ME compartment included only a few $\lg \mathrm{A}^{+}$and unswitched $\lg \mathrm{M}^{+} \lg \mathrm{D}^{-}$ ME cells, and these subsets did not increase overtime (Supplementary figure 4g). Consistent with our characterisation of B-cell subsets, RBDspecific extrafollicular ME B cells, or DN2, expanded during the acute phase of infection, but their frequency dramatically decreased in convalescence (Figure $4 \mathrm{~m}$ ). Of note, enrichment of $\lg \lambda$ usage was also observed in RBD-specific ME B cells and in $\lg \mathrm{A}^{+} \mathrm{PBs}$ (Supplementary figure $4 \mathrm{~h}, \mathrm{i}$ ).

To assess the persistency of virus-specific ME B-cell responses, RBD-targeting B-cell subsets were analysed by flow cytometry in a small cohort of non-hospitalised convalescent individuals 3 months (COVT3) and 6 months (COVT6) PSO (Supplementary figure 5). In agreement with previous reports, ${ }^{14,17,18}$ RBD-specific B cells persisted up to 6 months after infection (Supplementary figure $5 \mathrm{a}$ ) and mainly consisted of $\mathrm{IgG}^{+} \mathrm{ME} B$ cells (Supplementary figure 5b). Accordingly, RBDspecific IgG and, to a lesser extent, IgA were significantly higher in sera from COVT3 and COVT6 than in healthy controls (Supplementary figure $5 \mathrm{c}$ ). Thus, SARS-CoV-2 infection promotes a rapid and transient induction of RBD-specific PBs and extrafollicular ME B cells, as well as a long-lasting expansion of RBD-targeting activated naïve $B$ cells and IgG class-switched ME B cells.

\section{COVID-19 is associated with a sustained activation of $\mathrm{CD4}^{+}$and $\mathrm{CD8}^{+} \mathrm{T}$ cells}

To further characterise the dynamics of immune responses over time in COVID-19 patients, we 

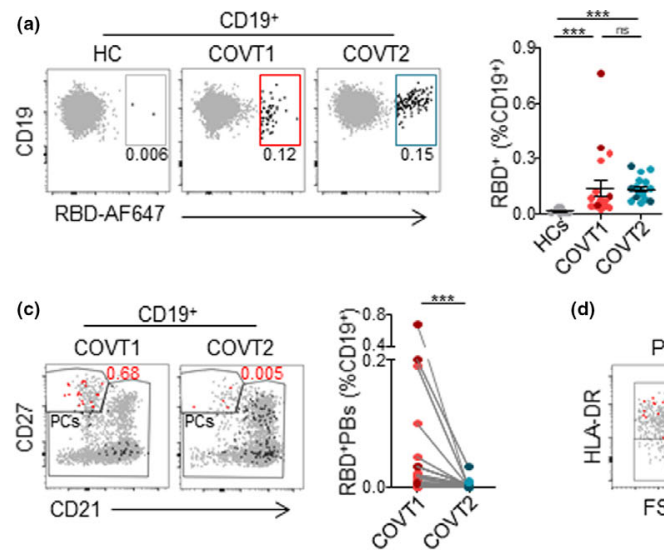

(d)

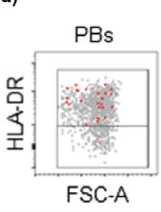

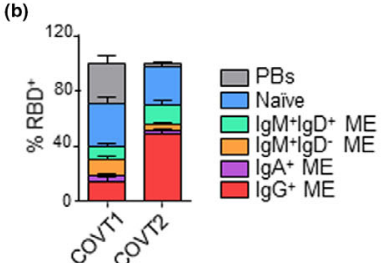

COVT1

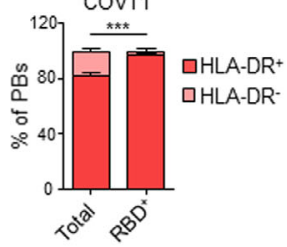

(g)

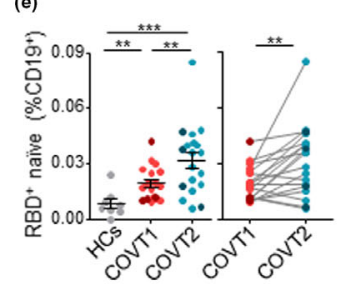

(f)

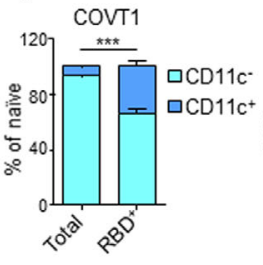

(i)

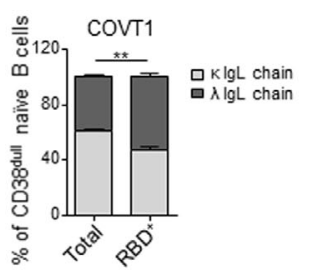

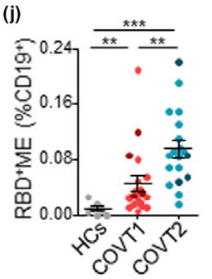

(k)

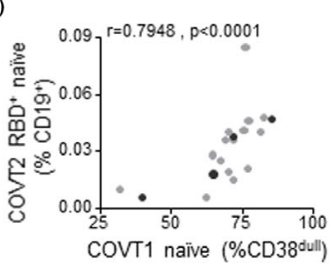

Naìve B cells
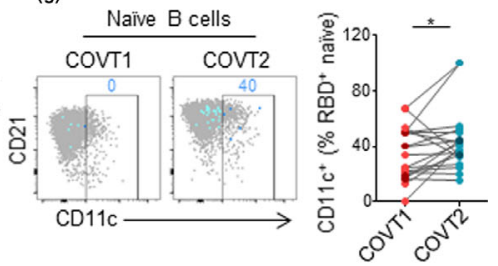
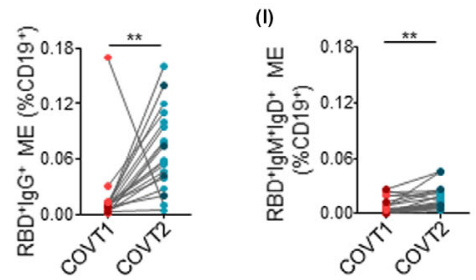
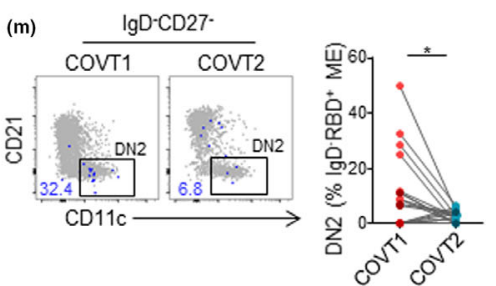

Figure 4. SARS-CoV-2 induces a temporal enrichment of RBD-specific plasmablasts in the early stage of infection and a sustained expansion of RBD-specific naïve and memory B-cell subsets. (a) Representative flow cytometric plots of CD19 $9^{+}$RBD-specific B cells (left) and frequency of RBD cells within total $C D 19^{+}$B cells (right) from each group of samples. Numbers indicate the percentage of RBD-specific cells within total CD19 $9^{+}$ cells. (b) Relative percentage of B-cell subsets within total RBD ${ }^{+}$CD19 $9^{+}$B cells in HCs, COVT1 and COVT2. (c) Representative flow cytometric plots and paired analysis of the frequency of RBD-specific PBs $\left(C D 19^{+} R B D^{+} C D 27^{++} C D 21^{-}\right)$within total $C D 19^{+} B$ cells. In the flow cytometric plot, red large dots represent RBD-specific PBs and numbers indicate percentage. (d) Representative flow cytometric plot and relative percentage of total and RBD-specific PBs expressing HLA-DR in COVT1. In the flow cytometric plot, red large dots represent RBD-specific PBs expressing HLADR. (e) Frequency and paired analysis of RBD-specific naïve B cells $\left(C D 19^{+} R_{B D}{ }^{+} C D 27^{-} \lg D^{+}\right)$within total CD19 $9^{+}$in HCs, COVT1 and COVT2. (f) Relative percentage of total or RBD-specific naïve B cells expressing CD11C in COVT1 samples. (g) Representative flow cytometric plots and paired analysis of the frequency of $C D 11 c^{+}$cells from RBD-specific naïve $B$ cells. Numbers indicate percentage of RBD-specific CD11 $c^{+}$naïve cells in the drawn gates. (h) Spearman's correlation analysis of naïve B cells in COVT1 and RBD ${ }^{+}$naïve B cells within CD19 ${ }^{+}$cells in COVT2. $r$ represents Spearman's rank-order correlation. (i) Relative percentage of total and RBD ${ }^{+}$naïve B cells expressing lambda or kappa light chains in COVT1. (j) Frequency of RBD-specific ME B cells defined as non-PB CD19+RBD ${ }^{+}$IgD ${ }^{-}$from total CD19+ $B$ cells in HCs, COVT1 and COVT2. (k) Paired analysis of the frequency of RBD-specific $\operatorname{lgG}^{+} \mathrm{ME} B$ cells defined as $\lg \mathrm{A}^{-} \lg \mathrm{M}^{-} \lg \mathrm{D}^{-}$within total $\mathrm{CD} 19^{+}$in COVT1 and COVT2. (l) Paired

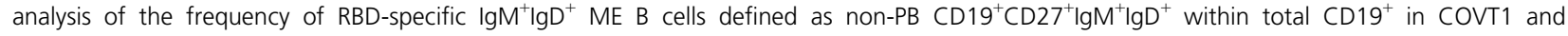
COVT2. (m) Representative flow cytometric plots and paired analysis of the frequency of DN2 ME B cells (non-PB $C D 19^{+} R_{B D}{ }^{+} C D 27^{-} \mid g D^{-} C D 11 c^{+}$) from total IgD ${ }^{-} \mathrm{RBD}^{+} \mathrm{ME} B$ cells. Numbers indicate percentages of RBD-specific DN2 ME in the drawn gates. Dark-coloured dots show ICU patients. Bars represent mean \pm SEM. The two-tailed Mann-Whitney U-test was performed to compare HCs with COVT1 and HCS with COVT2. The Wilcoxon matched-pairs test was performed to compare COVT1 with COVT2. ns, non-significant $(P>0.05), * P<0.05, * * P<0.01$ and $* * * P<0.001$. HCs, $n=11 ;$ COVT1, $n=19 ;$ COVT2, $n=19$. 
simultaneously analysed by multicolour spectral flow cytometry the phenotypic landscape of other circulating lymphoid and myeloid populations using an in-house-developed 23-colour antibody panel (Supplementary table 4). The projection of the data for $\mathrm{CD}_{19} \mathrm{CD}^{+}$cells in tSNE space allowed the definition of the main T-cell subsets, the contribution of each group of samples to Tcell populations and the expression patterns of relevant T-cell surface proteins (Figure $5 \mathrm{a}, \mathrm{b}$ and Supplementary Figure 6a). In parallel, we queried the data by traditional gating (Supplementary figure $6 b-d)$. As reported previously, ${ }^{12,35}$ the acute phase of infection was characterised by a striking reduction in the frequency of $\mathrm{CD}^{+} \mathrm{T}$ cells (Figure 5c), which was driven by a decrease in the frequency of $\mathrm{CD}^{+}$and, to an even larger extent, $\mathrm{CD}^{+} \mathrm{T}$ cells (Supplementary figure $7 \mathrm{a}, \mathrm{b}$ ). Compared with healthy controls, convalescent individuals still had a significantly decreased frequency of $\mathrm{CD}^{+}$cells (Figure $5 \mathrm{c}$ ) and in particular of $\mathrm{CD}^{+} \mathrm{T}$ helper cells (Supplementary figure 7a), which suggested their persistent loss from the periphery. We then evaluated how SARS-CoV-2 infection associated with temporary or long-lasting perturbations in both CD4 and CD8 T-cell compartments. Interestingly, the frequency of naïve $T$ cells within total $\mathrm{CD}^{+} \mathrm{T}$ cells was significantly lower in acutely infected patients than in age-matched healthy controls and further declined during convalescence (Figure 5d). This reduction was associated with a prominent expansion of activated $\mathrm{CD}^{+} 8^{+} \mathrm{HLA}-\mathrm{DR}^{+} \mathrm{CD}^{+} \mathrm{T}$ cells during acute infection and, to a lesser extent, in convalescence (Figure 5e), as observed in other viral infections. ${ }^{36,37}$

We then analysed the frequency of circulating $T$ follicular helper (cTfh) cells. Tfh cells are a specialised subset of $\mathrm{CD}^{+} \mathrm{T}$ cells that provide cognate help to antigen-specific $B$ cells in the germinal centre (GC) to initiate and maintain humoral immune responses. ${ }^{38}$ These cells include a circulating counterpart, cTfh cells, which coexpress PD-1 and CXCR5 as their GC-based equivalents do (Supplementary figure 6c). In general, cTfh cells can be used as a surrogate to evaluate the Tfh cell activity in lymphoid tissues. ${ }^{39}$ Of note, activated $\mathrm{CD}^{2} 8^{+} \mathrm{ICOS}^{+}$CTfh cells likely reflect a recent exit from the GC immediately after antigen encounter. ${ }^{40}$ The frequency of cTfh cells was significantly higher in COVT2 patients than in healthy controls and COVT1 patients, which is consistent with a model of antigen persistency and long-lasting GC reaction previously suggested by others ${ }^{22}$ (Figure 5f). Interestingly, recently activated ${\mathrm{CD} 38^{+}}^{+} \mathrm{COS}^{+} \mathrm{cTfh}$ cells were more profoundly increased during the acute phase, which probably reflects the peak of $\mathrm{GC}$ responses in the early phase of the infection (Figure 5g).

We further explored whether SARS-CoV-2 infection promoted perturbations of other $\mathrm{CD}^{+}$ helper T-cell subsets, including central memory (CM) T cells, effector memory (EM) 1, 2 and $3 \mathrm{~T}$ cells, terminally differentiated effector memory (EMRA) $T$ cells, $T$ regulatory (Treg) cells and $T$ helper 1 (Th1), Th1/17, Th2 and Th17 cells (Supplementary figure 6b). We detected an increase in the frequency of Treg cells during the acute phase of infection and a small but significant increase in the frequencies of Th1 and Th1/17 cells in COVT2 compared with COVT1 upon pairwise comparison, whereas Th2 cells showed a decreased frequency over time (Supplementary figure $7 c$ ).

COVID-19 was also associated with several changes in the $\mathrm{CD}^{+}{ }^{+}$-cell compartment. We observed a significantly reduced frequency of naïve $\mathrm{CD} 8^{+} \mathrm{T}$ cells during convalescence and an expansion of $\mathrm{CM}$ and $\mathrm{EM} 3 \mathrm{CD}^{+} \mathrm{T}$ cells (Figure $5 \mathrm{~h}-\mathrm{j}$ ). However, our analysis showed no differences in the frequency of EM1, EM2 and EMRA $C D 8^{+} \mathrm{T}$ cells between groups (Supplementary figure 7d). We also found that activated $\mathrm{CD} 38^{+} \mathrm{HLA}^{-D R^{+} \mathrm{CD} 8^{+} \mathrm{T}}$ cells strongly expanded during the acute phase of infection and still persisted at a higher frequency during convalescence compared with healthy controls (Figure 5k). As expected, patients with a greater increase in activated $\mathrm{CD}^{+} \mathrm{T}$ cells also showed a higher frequency of activated $\mathrm{CD}^{+} \mathrm{T}$ cells (Figure 5I). Thus, SARS-CoV-2 causes a marked T-cell loss during the acute phase of infection, which is associated with long-lasting and coordinated activation of $\mathrm{CD}^{+}$and $\mathrm{CD}^{+} \mathrm{T}$ cells and expansion and activation of professional B-cellhelping T cells.

\section{SARS-CoV-2 infection drives profound changes in the innate immune compartment}

Acute SARS-CoV-2 infection triggers alterations in circulating innate immune cell subsets, some of which have been associated with COVID-19 severity. ${ }^{41}$ Nevertheless, how these perturbations persist during convalescence after viral clearance is unclear. We combined global high-dimensional 
(a)

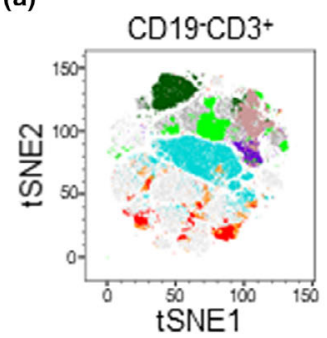

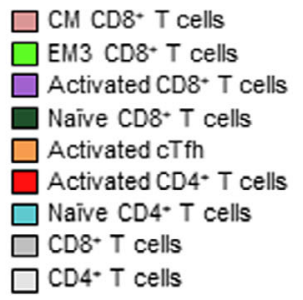

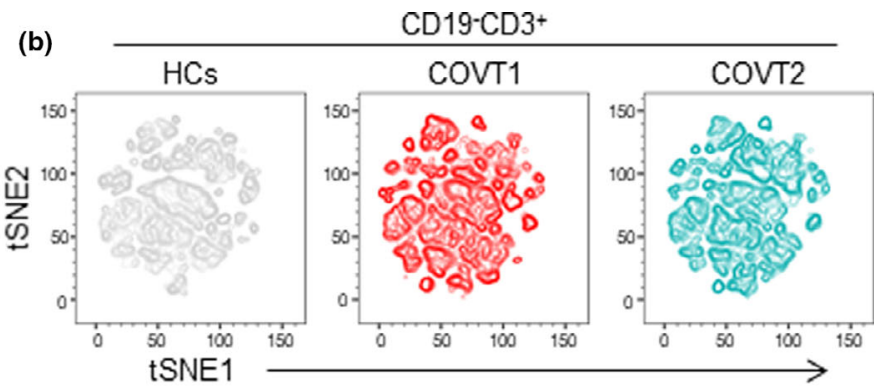

(c)

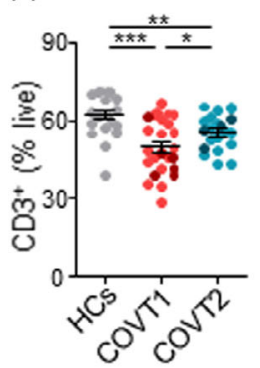

(f)

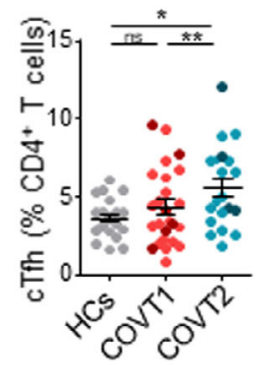

(d)

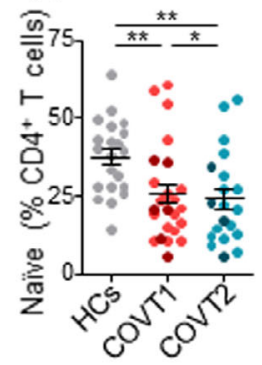

(g)

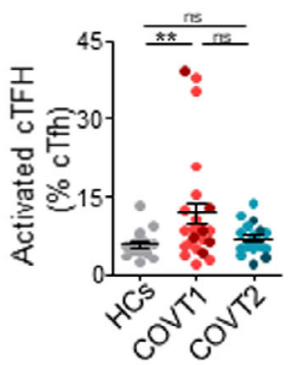

(e)

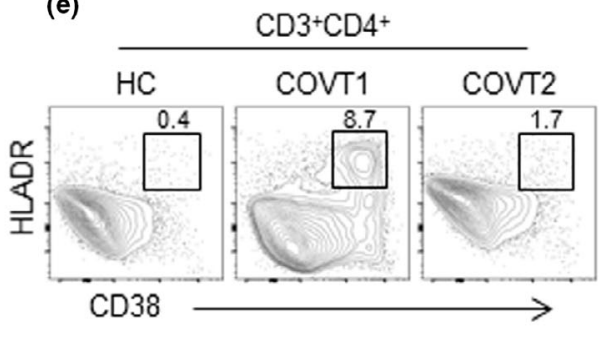

(h)

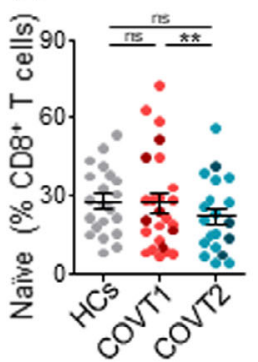

(i)

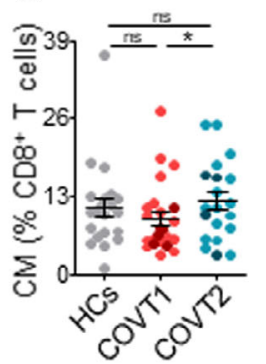

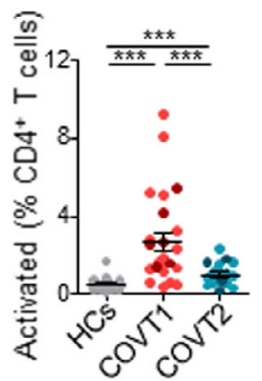

(j)

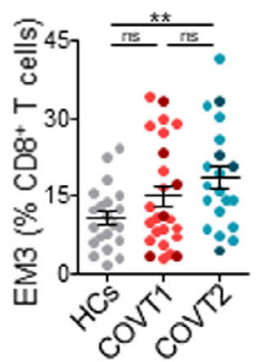

(k)

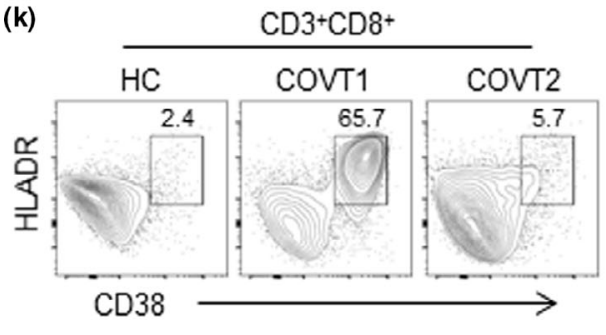

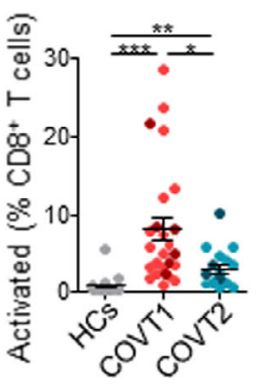

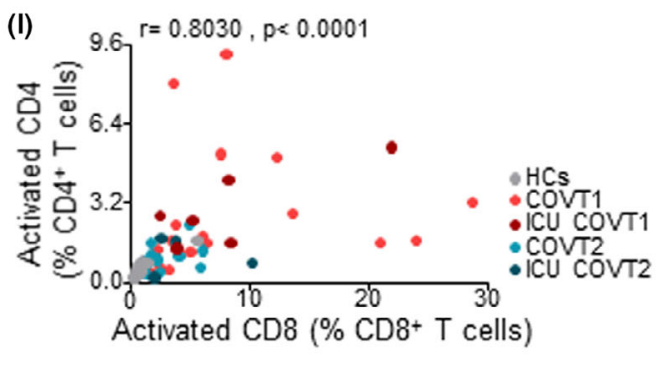

Figure 5. COVID-19 is associated with long-lasting contraction of naive T-cell compartment, CD4 ${ }^{+}$and $C D 8^{+}$T-cell activation, and expansion of circulating T follicular helper cells. (a) Merged tSNE projection of CD3 $3^{+}$cells for healthy controls (HCs; $\left.n=21\right)$, COVT1 $(n=25)$ and COVT2 $(n=20)$ donors concatenated, with main T-cell populations indicated by colour. CM, central memory. EM, effector memory. cTfh, circulating T follicular helper $\mathrm{T}$ cells. (b) tSNE projections of $\mathrm{CD}^{+} \mathrm{T}$ cells for each sample group. (c) Frequency of $\mathrm{CD}^{+} \mathrm{T}$ cells within live lymphocytes. (d) Frequency of naive $C D 4^{+} T$ cells $\left(C D 27^{+} C D 45 R A^{+} C C R 7^{+}\right)$from total $C D 4^{+} T$ cells. (e) Representative flow cytometric plots (left) and frequency of $\mathrm{CD} 38^{+} \mathrm{HLA}-\mathrm{DR}^{+}$-activated $\mathrm{CD4} 4^{+} \mathrm{T}$ cells within total $\mathrm{CD} 4^{+} \mathrm{T}$ cells. Numbers indicate percentages in the drawn gates. (f) Frequency of circulating cTfh cells (non-naive $C X C R 5^{+} \mathrm{PD}-1^{+}$) within total $\mathrm{CD} 4^{+} \mathrm{T}$ cells. (g) Frequency of activated $\mathrm{CTfh}$ cells $\left(\mathrm{CD} 8^{+} \mathrm{ICOS} \mathrm{S}^{+}\right.$) within total cTfh cells. (h)

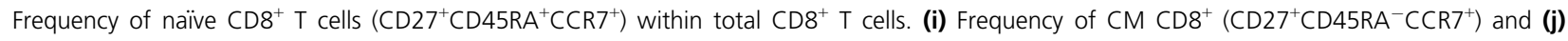
EM3 (CD27- ${ }^{-}$D45RA $\left.{ }^{-} C C R 7^{-}\right)$T-cell subsets within total $C D 8^{+}$T cells. (k) Representative flow cytometric plots and frequency of $C D 38^{+} H L A-D R^{+}-$ activated $C D 8^{+} T$ cells within total $C D 8^{+} T$ cells. Numbers indicate percentages in the drawn gates. (l) Spearman's correlation analysis of activated $\mathrm{CD}^{+} \mathrm{T}$ and $\mathrm{CD} 8^{+} \mathrm{T}$ cells in all samples analysed. $\mathrm{r}$ represents Spearman's rank-order correlation. (c-k) Data are presented as individual dots. Dark-coloured dots show ICU patients. Bars represent mean \pm SEM. The two-tailed Mann-Whitney U-test was performed to compare HCs with COVT1 and HCS with COVT2. The Wilcoxon matched-pairs test was performed to compare COVT1 with COVT2. ns, non-significant $(P>0.05)$, $* P<0.05, * * P<0.01$ and $* * * P<0.001$. HCS,$n=21 ;$ COVT1, $n=25 ;$ COVT2, $n=20$. 
mapping via tSNE of $\mathrm{CD}^{-} 9^{-} \mathrm{CD}^{-}$cells with traditional gating analysis to study significant alterations in the phenotype and frequency of peripheral blood innate immune cell subsets in COVT1 and COVT2 compared with healthy controls (Figure 6a, b and Supplementary figure $8 a, b)$. Although the frequency of total circulating $\mathrm{CD} 11 \mathrm{c}^{+} \mathrm{HLA}-\mathrm{DR}^{+}$myeloid cells among live PBMCs in COVT1 and COVT2 was comparable to that of healthy controls (Supplementary figure 8c), we observed significant differences in the phenotype and subset composition of these myeloid cells. We initially explored the expression of the activation-induced molecule CD38 and HLA-DR on circulating myeloid cells. We found a striking induction of CD38 and a reduction in the expression of HLA-DR during acute infection (Figure 6c, d). Of note, the decrease in HLA-DR may interfere with proper antigen presentation and has been directly linked to an immunosuppressive phenotype of monocytes during sepsis. ${ }^{5}$ Indeed, HLA-DR levels strongly correlated with disease severity defined according to the patient's oxygen requirement (Supplementary figure 8d). However, these changes were only transient, as CD38 and HLA-DR returned to their homeostatic expression levels in the convalescent phase (Figure $6 c, d$ ).

We then analysed the frequency of $\mathrm{CD} 14^{+} \mathrm{CD} 16^{-}$ conventional monocytes, $\mathrm{CD} 14^{+} \mathrm{CD} 16^{+}$ intermediate monocytes and $\mathrm{CD} 14^{\operatorname{dim}} \mathrm{CD} 16^{+}$nonconventional monocytes. Classical $\mathrm{CD} 14^{+} \mathrm{CD} 16^{-}$ monocytes remained unaltered, whereas intermediate $\mathrm{CD}_{14} \mathrm{CD}^{+} 6^{+}$monocytes showed a higher frequency in COVT2 than in COVT1 and healthy controls (Supplementary figure 8e, f). Furthermore, we observed a robust but transient decrease in the frequency of non-conventional $\mathrm{CD} 14^{\text {dim }} \mathrm{CD} 16^{+}$monocytes (Figure 6e), which appeared to be strongly activated during acute infection (Figure 6f). Non-conventional monocytes have a patrolling function and contribute to the antiviral response, ${ }^{42}$ which may point to their selective recruitment to the inflamed lung upon Fc $\gamma$ RIIIA-mediated activation by virus-IgG immune complexes. Accordingly, non-conventional monocytes have been shown to be enriched in the lungs of critical COVID-19 patients. ${ }^{43}$ The frequency of circulating myeloid dendritic cells ( $\mathrm{mDCs})$ and basophils was also strongly reduced in COVT1 compared with healthy controls, but both returned to homeostatic levels two months PSO (Figure $6 \mathrm{~g}$, h). Interestingly, we detected increased CD25 expression on basophils from COVT1 compared with COVT2, which suggests basophil activation during the acute phase of infection (Supplementary figure $8 \mathrm{~g}$ ).

Finally, we analysed the frequency of circulating plasmacytoid DCs (pDCs) and natural killer (NK) cells, two subsets of the innate immune system that play crucial protective roles in viral infections. As reported previously, ${ }^{44}$ the frequency of pDCs significantly decreased during acute infection (Figure 6i). Remarkably, convalescent individuals maintained significantly lower frequency of pDCs compared with healthy controls, even after viral clearance (Figure 6i), suggesting persistent impaired type I IFN responses in infected individuals.

Although our data did not reveal any significant changes in the frequencies of natural killer (NK) cells within live cells, the analysis of CD38 expression indicated an activated phenotype during the acute phase of the infection (Figure $6 \mathrm{j}$, k). Moreover, the characterisation of NK cell subsets based on the relative expression of CD56 and CD16 showed a persistent decrease in the frequency of circulating immature $\mathrm{CD} 56^{\text {bright }} \mathrm{CD} 16^{-}$cells and an increase in the proportion of naturally cytotoxic $\mathrm{CD} 56^{\mathrm{dim}} \mathrm{CD} 16^{\text {high }}$ cells within total NK cells (Figure 6I and Supplementary figure 8h). Thus, SARS-CoV-2 infection drives profound changes in the circulating innate immune compartment, some of which persist after viral clearance during convalescence.

\section{High-dimensional analysis reveals coordinated immune responses and their association with disease severity}

The immune system is composed of layered defence mechanisms of increasing specificity that protect the host from infection. To investigate the putative associations between innate and adaptive immune trajectories developed upon SARS-CoV-2 infection, we performed pairwise correlations across 41 variables that were significantly different among the groups analysed, including virus-specific antibody titres measured by ELISA and selected immune parameters identified by high-dimensional flow cytometry (Supplementary data file 1). We found that the global antibody response to SARS-CoV-2 positively correlated with the frequency of circulating PBs, extrafollicular DN2 ME B cells, activated $\mathrm{CD}^{+}{ }^{+} \mathrm{T}$ 
(a)

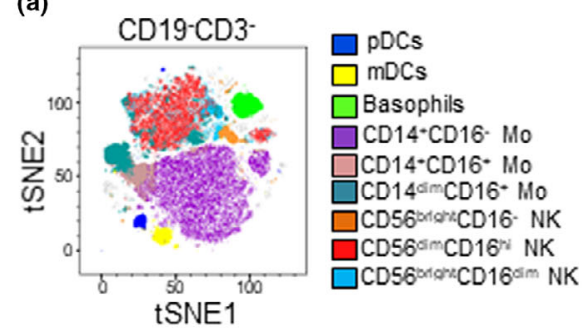

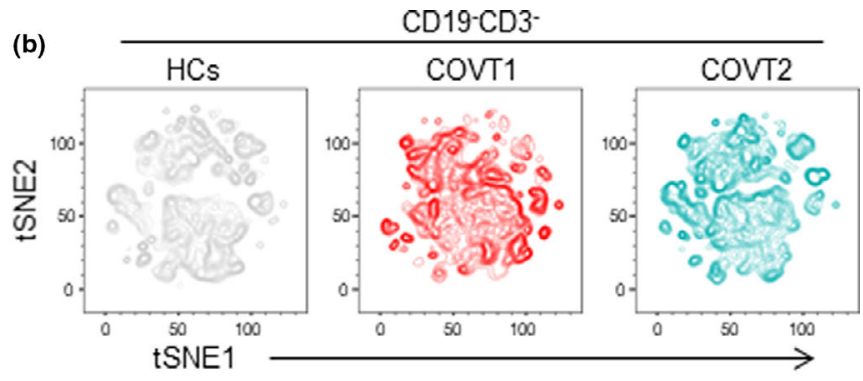

(e)

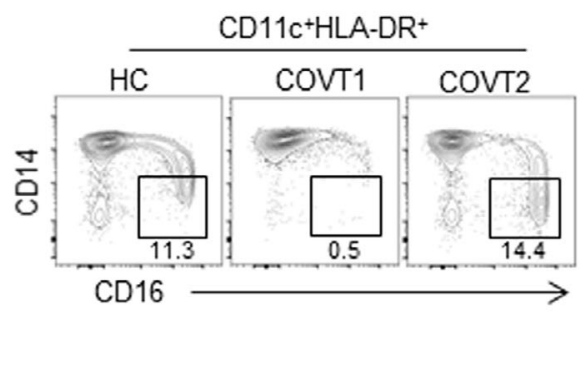

(h)

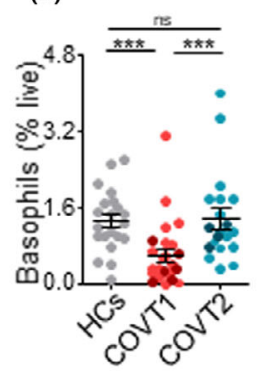

(i)

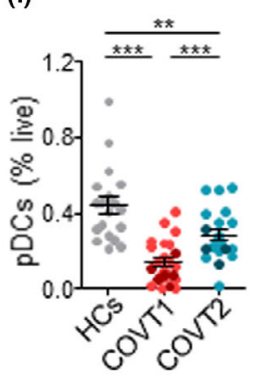

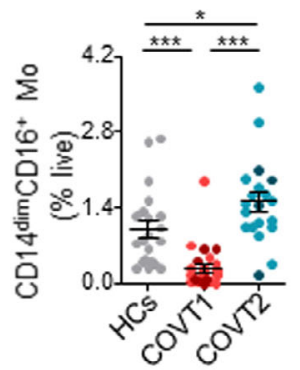

(j)

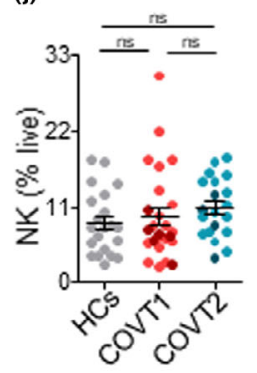

(k)

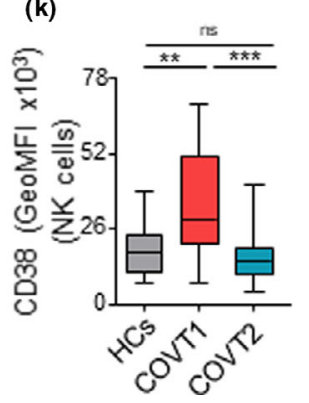

(g)

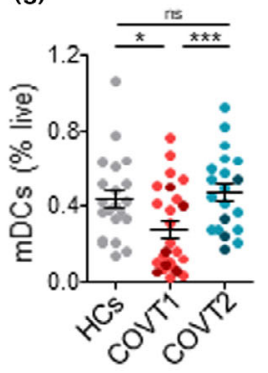

(I)

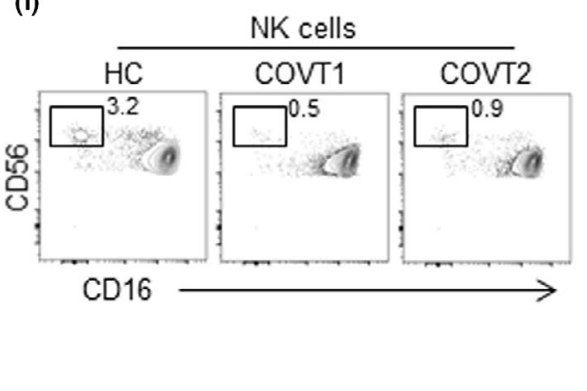

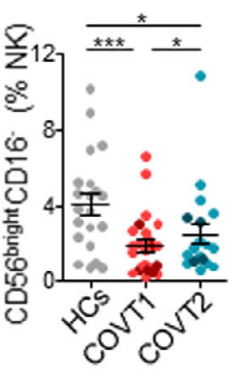

Figure 6. SARS-COV-2 infection associates with transitory and long-lasting changes in the innate immune compartment. (a) Merged tSNE projection of $\mathrm{CD}_{19} \mathrm{CD}^{-}$cells for healthy controls $(\mathrm{HCS} ; n=21)$, COVT1 $(n=25)$ and COVT2 $(n=20)$ samples concatenated and overlaid, with main innate immune cell populations indicated by colour. pDCs, plasmacytoid dendritic cells. mDCs, myeloid dendritic cells. Mo, monocytes. NK, natural killer cells. (b) tSNE projections of $\mathrm{CD}_{19^{-}} \mathrm{CD}^{-}$innate immune cells for each sample group. (c) Geometric mean fluorescence intensity (GeoMFI) of CD38 and (d) HLA-DR expression in CD19- CD3 ${ }^{-}$CD11 $\mathrm{c}^{+}$myeloid cells from HCs, COVT1 and COVT2. (e) Representative flow cytometric plots and frequency of non-classical $C D 14^{\operatorname{dim}} C D 16^{+}$Mo as a proportion of live cells. Numbers indicate percentages in the drawn gates. (f) GeoMFI of CD38 in CD14 ${ }^{\operatorname{dim}} \mathrm{CD} 16^{+}$Mo. (g) Frequency of mDCs, (h) basophils, (i) pDCs and (j) NK cells within total live cells. (k) GeoMFI of CD38 in NK cells. (I) Representative flow cytometric plots and frequency of CD56 bright $C D 16-$ NK cells. Numbers indicate percentages in the drawn gates. Data are presented as individual dots. Dark-coloured plots show ICU patients. Bars represent mean \pm SEM. Two-tailed Mann-Whitney U-test was performed to compare HCs with COVT1 and HCs with COVT2. The Wilcoxon matched-pairs test was performed to compare COVT1 with COVT2 ( $\mathbf{c}, \mathbf{d}, \mathbf{f}$ and $\mathbf{k}$ ). Data are presented in boxplots. Box boundaries represent the 1st and 3rd quartile of the distribution, while the centre line represents the 2 nd quartile (median). Whiskers go down to the smallest value and up to the largest. ns, nonsignificant $(P>0.05), * P<0.05, * * P<0.01$ and $* * * P<0.001$. HCs, $n=21 ;$ COVT1, $n=25 ;$ COVT2, $n=20$. 
cells, cTfh cells and $\mathrm{CD} 8^{+} \mathrm{T}$ cells. It also positively correlated with CD38 expression on circulating myeloid cells, which suggests a close coordination between innate and adaptive immune responses. However, the level of virus-specific antibody titres, the percentage of circulating PBs and the frequency of $\mathrm{CD} 19^{+}$cells inversely correlated with the frequency of $\mathrm{CD}^{+} \mathrm{T}$ cells, non-conventional monocytes and $\mathrm{pDCs}$, which suggests virusinduced interference with different components of both adaptive and innate immune responses in a fraction of COVID-19 patients (Figure 7a). Next, principal component analysis (PCA) was performed to examine the general distribution of healthy controls and infected individuals during acute and convalescent stage according to these immune parameters. The analysis revealed that patients during acute infection were notably more distant from healthy controls than the same patients during convalescence in PCA space (Figure 7b). Virus-specific IgA titres, as well as the frequency of IgG and IgM PBs, activated CD4 T cells and $\mathrm{pDCs}$, were among the variables that mostly contributed to the observed clustering in PC1 space. The frequency of naïve B cells and, to a lesser extent, $\operatorname{lgM}^{+} \lg D^{+} \mathrm{ME} B$ cells, $\lg \mathrm{A} 1 \mathrm{PBs}$ and NP-specific IgM titres was the immune features that mostly contributed to the clustering in $\mathrm{PC2}$ space (Figure $7 c, d$ ). We then used the first two principal components of the PCA to compute the Euclidean distance of all COVT1 to the centroid of the healthy controls. Remarkably, we found a positive correlation between this distance and disease severity defined according to the patient's oxygen requirement and serum concentration of ferritin and lactate dehydrogenase during acute infection (Figure 7e). Of note, the same analysis performed computing the Euclidean distance of COVT2 samples to the centroid of the healthy controls did not show equivalent correlation patterns (Supplementary figure 9), which suggests that immunological recovery trajectories in convalescence occur independently of disease severity status during acute infection. Thus, crossdata set correlation and principal component analyses reveal coordinated immune responses in COVID-19 patients and immune parameters associated with disease severity and inflammation.

\section{DISCUSSION}

A better understanding of immune changes occurring during COVID-19 progression and recovery is required to predict disease outcome and development of long-lasting immune protection. The vast majority of studies so far have focused on the immune profiling of elderly COVID-19 patients, who have an intrinsic risk to develop severe disease because of ageing of the immune system and potential underlying health conditions. To circumvent this bias, we selected hospitalised patients younger than 65 and compared their immune parameters with equivalent parameters from age-matched healthy controls. This approach provided new insights into the breadth and kinetics of virus-specific B-cell responses to SARS-CoV-2 and on the immunological landscape of not aged COVID-19 patients ranging from moderate to severe.

During acute SARS-CoV-2 infection, the presence of virus-specific antibodies with highly diversified Fc receptor-associated effector functions is consistent with an early involvement of multiple systemic and mucosal mechanisms of humoral protection, which presumably include immune pathways emerging from the gut. ${ }^{45}$ The observed decline in RBD- and NP-specific IgM, $\lg A 1$ and $\lg A 2$ and the progressive increase in RBD-specific lgG1 during convalescence may reflect two temporal phases of humoral immunity to SARS-CoV-2: an initial stage characterised by a rapid release of poorly mutated and highly diversified antibody classes and subclasses, largely produced by short-lived PBs through extrafollicular pathways, followed by the emergence of high-affinity IgG released by longlived plasma cells presumably emerging from GCs. Indeed, the analysis of virus-specific B-cell subset dynamics showed a transient increase in circulating RBD-specific HLA-DR ${ }^{+}$PBs and extrafollicular DN $B$ cells in acute infection, followed by the waning of early non-GC-derived $B$-cell responses and sustained expansion of virusspecific IgG-dominated B-cell memory. This breadth and kinetics of humoral responses may be set in place to consolidate robust antibody responses aimed at achieving complete viral clearance and long-lasting immune protection. Indeed, immune inhibitory signals generated by systemically produced monomeric IgA via the FcaRI receptor could interfere with the clearance of IgG-opsonised viral particles by phagocytes at a later phase of the infection. When engaged by monomeric forms of systemic IgA, the $\mathrm{Fc} \alpha \mathrm{RI}$ receptor predominantly deploys inhibitory ITIMmediated signals to phagocytes and NK cells. ${ }^{46}$ 

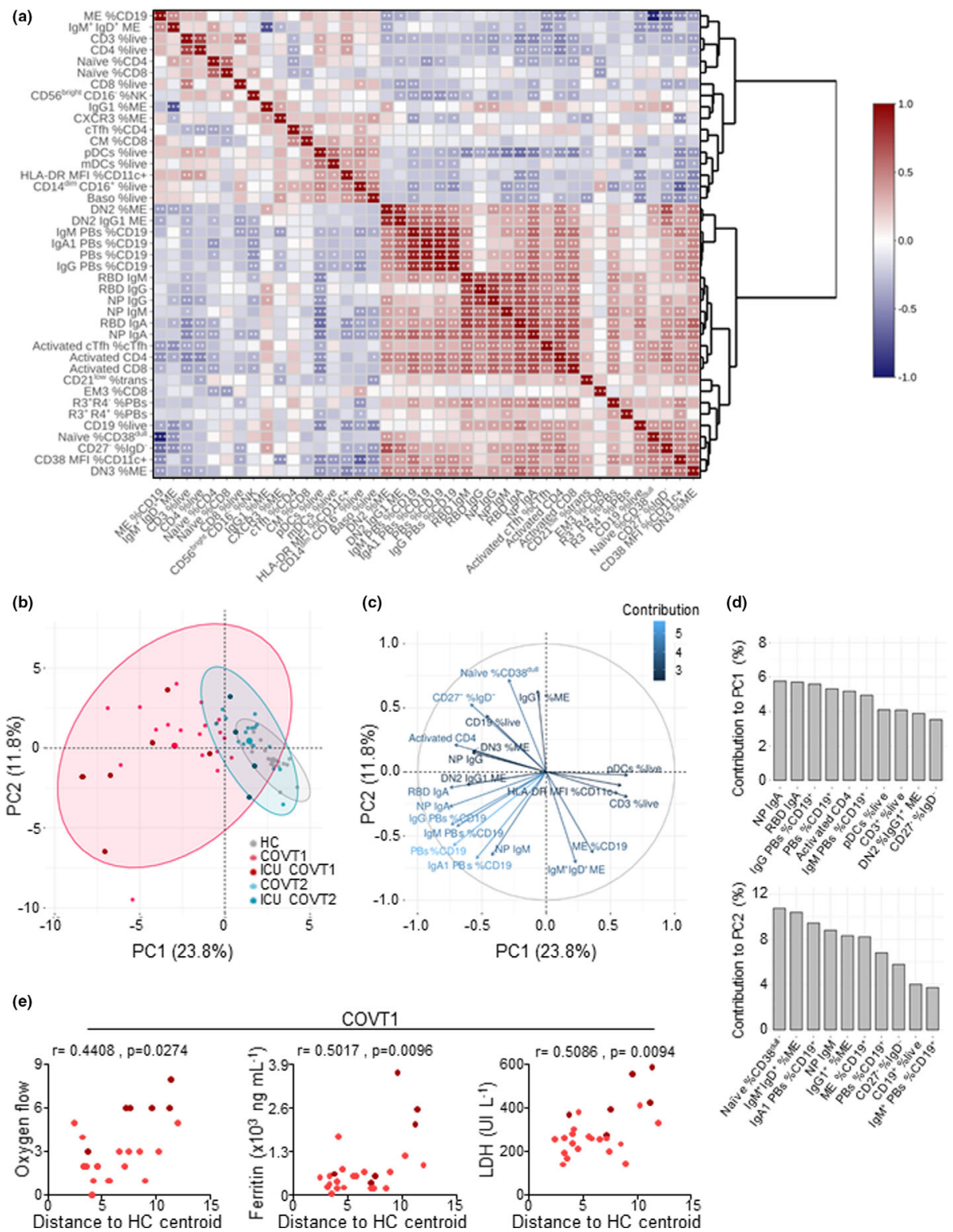

(e)

COVT1
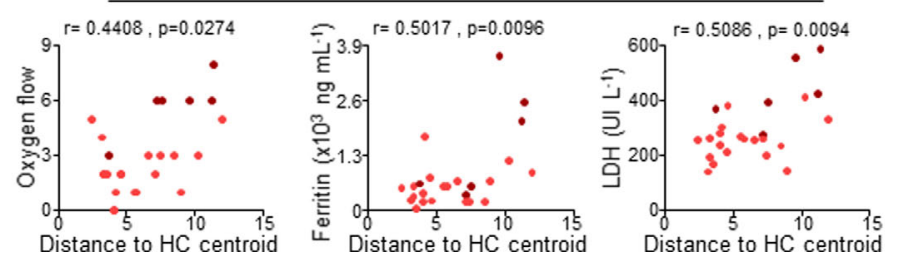

Figure 7. High-dimensional analysis of all variables studied reveals coordinated immune responses and their association with disease severity (a) Spearman's correlation mapping of indicated parameters for healthy controls (HCs), COVT1 and COVT2. Spearman's rank correlation coefficient ( $\rho$ ) was indicated by heat scale; Spearman's $P$-value significance levels were corrected using the Benjamini-Hochberg method significance $(* P<0.05, * * P<0.01$ and $* * * P<0.001)$. PBs, plasmablasts. R3, CXCR3. R4, CXCR4. ME, memory. cTfh, circulating T follicular helper cells. CM, central memory. EM3, effector memory type 3. pDCs, plasmacytoid dendritic cells. mDCs, myeloid dendritic cells. Baso, basophils. NK, natural killer cells. trans, transitional B cells. (b) Principal component analysis (PCA) based on antibody titres, frequencies and GeoMFI of all measured markers (centred and scaled). RBD-specific parameters were excluded from the analysis. The first component explains $25 \%$ of the variation, whereas the second component explains $12.3 \%$ of the variation. Each dot represents a donor, and each colour represents a donor group. Darkcoloured dots show ICU patients. Confidence ellipses for each group are plotted (confidence level set to 95\%). (c) Variable correlation plot showing eigenvector-based coordinates of the top 20 variables in the two-dimensional space defined by the first two principal components. The relative position of the clinical variables reflects their relationship (positive correlated variables point to the same side of the plot; negative correlated variables point to opposite sides of the plot), while the length of the arrow is proportional to their contribution to the principal components. (d) Relative contribution of the top 10 variables to PC1 (top panel) and PC2 (bottom panel). (a-d) HCs, $n=16$; COVT1, $n=25$; COVT2, $n=20$. (e) Spearman's correlation analysis of oxygen flow, ferritin and lactate dehydrogenase (LDH) levels in COVID-19 patients at COVT1 plotted against the Euclidean distance computed using the two first principal components from the PCA of each COVT1 patient to the centroid of the healthy control (HC) group. The HC centroid is computed by averaging PC1 and PC2 for all HCs. Data are presented as individual dots. Dark-coloured dots show ICU patients. $r$ represents Spearman's rank-order correlation. 
Another possible explanation for the reduction in virus-specific $\lg \mathrm{A} 1$ and $\lg \mathrm{A} 2$ two months PSO is the relocation of IgA-secreting $\mathrm{PBs}$ to mucosal inflamed tissues, including the upper respiratory tract. Indeed, acutely infected patients showed increased proportion of $\mathrm{CXCR3}^{+} \mathrm{CXCR} 4^{-}$PBs that are programmed to migrate to inflamed tissues rather than bone marrow niches. Consistently, two earlier reports described elevated SARS-CoV-2specific IgA antibodies in nasal fluids, tears and saliva of infected individuals. ${ }^{27,47}$ However, a recent study failed to detect PBs in the lung of deceased COVID-19 patients. ${ }^{48}$

Overall, our data are in agreement with recent reports showing detectable S-specific IgG and neutralising antibodies at 6-8 months PSO and rapid decline in circulating $\lg A$ titres. ${ }^{14-18}$ Moreover, we provided additional information on the dynamics of SARS-CoV-2-specific IgG subclasses in different phases of the infection. Compared with healthy controls, COVID-19 patients showed higher titres of all RBD- and NP-specific IgG subclasses, including poorly reported IgG2 and IgG4 subclasses, during acute infection and convalescence. Yet, only RBD-specific IgG1 increased over time, presumably because this antibody mostly originated from delayed GC responses. Finally, the magnitude and kinetics of IgG subclasses were highly heterogeneous between infected individuals. Thus, more studies with larger cohorts and later time points are required to explore the contribution of each IgG subclass to immune protection and recovery trajectories.

Recent reports have shown sustained development of virus-targeting ME $B$ cells expressing IgG and a continuous evolution of the virus-specific antibody repertoire over time, ${ }^{14,16,17}$ indicating that SARS-CoV-2 infection promotes long-lasting GC-derived humoral responses. Similarly, we detected a sustained increase in RBDspecific IgG ME B cells that lasted for 6 months PSO. In addition, our analysis revealed that SARSCoV-2 infection profoundly shaped the overall Bcell memory compartment, promoting a sustained increase in the $\operatorname{lgG} 1^{+} \mathrm{ME}$ subset and a persistent contraction of unswitched $\mathrm{CD}^{2} 7^{+} \operatorname{lgM}^{+} \operatorname{IgD}^{+} \mathrm{ME} B$ cells. Loss of $\mathrm{IgM}^{+} \mathrm{ME} B$ cells in COVID-19 patients has been previously described and associated with increased mortality and superimposed infections. ${ }^{49}$ However, in our cohort of COVID-19 patients, the frequency of $\mathrm{CD}^{2} 7^{+} \operatorname{lgM}{ }^{+} \lg \mathrm{D}^{+} \mathrm{ME}$ B cells positively correlated with several markers of inflammation and NP-specific IgM titres. These results suggest that, in a subset of patients, humoral responses might diverge towards less efficient and nonneutralising NP-targeting antibodies. These antibodies may arise from the reactivation of Bcell subsets primed during previous seasonal coronavirus infections and therefore expressing cross-reactive but poorly protective IgM.

The mapping of global and SARS-CoV-2-specific B-cell subsets in COVID-19 patients younger than 65 years also revealed some striking changes in mature B-cell precursors. The increased frequency in $\mathrm{CD} 21^{\text {low }}$ transitional and naïve B cells in COVT1 patients compared with age-matched healthy controls and COVT2 patients was consistent with the mobilisation of B-cell precursors to the periphery following virus-induced inflammation. ${ }^{30}$ In the presence of massive immune sensing of viral particles, the immune system may be evolutionary programmed to recruit mature B-cell precursors from the bone marrow into the periphery as a 'last-ditch' defence against invading virions. Multiple inflammation-induced cytokines, including IL-7, may contribute to this process. ${ }^{33}$

In agreement with this hypothesis, we documented a significant expansion of RBDspecific naïve $B$ cells enriched in $\lg \lambda$ that were largely activated and more numerous in COVID-19 patients with increased serum IL-7 and expanded naive $B$ cells. Acute infection was also characterised by an increased proportion of immature $\mathrm{CD} 21^{\text {low }}$ transitional $\mathrm{B}$ cells and, as recently reported, ${ }^{25}$ an increase in serum BAFF, an homeostatic regulator of peripheral $B$ lymphopoiesis. Altogether, these results support a scenario where the de novo recruitment of mature B-cell precursors to the periphery promotes the emergence of $B$ cells expressing virus-reactive specificities constitutively engraved in the germline repertoire.

Consistent with this interpretation, stereotypic neutralising antibodies with no or very few somatic mutations have been recently described in both the naive and ME B-cell repertoires from COVID-19 patients. ${ }^{20-25}$ Antibodies expressed by naïve and transitional $B$ cells have notoriously different structural properties compared with mature antibodies expressed by GC-selected B cells. Compared with the latter, naive and transitional B cells express antibodies that have a generally longer H-CDR3 in addition to increased autoreactivity and polyreactivity. ${ }^{50}$ These properties may be central to the initial 
recognition and neutralisation of the RBDcontaining $S$ protein on SARS-CoV-2. Antigenactivated naive and transitional $B$ cells could then transit through the GC to increase their affinity for viral antigens while redeeming their potential harmful autoreactivity. Therefore, the expansion of a naïve B-cell repertoire expressing BCRs reactive to a wider range of neutralising epitopes across the RBD of the $S$ antigen may confer a functional advantage with respect to the initiation of protective antibody responses to SARS-CoV-2. However, the mobilisation of B-cell precursors to the periphery could also promote the emergence of pathogenic antibody responses to self-antigens because of defective central tolerance. $^{30,50}$ Indeed, the frequency of naïve B cells was a key variable to define distinct immune signatures associated with disease severity and inflammation in COVID-19 patients. More studies are needed to evaluate longitudinal changes in the naïve Ig repertoire upon infection and their putative correlation with the onset of autoimmunity.

To further characterise the coordination of humoral immunity with other arms of the immune system in COVID-19 patients, we analysed other circulating lymphoid and myeloid populations. Consistent with recent studies, ${ }^{12,51}$ we showed robust activation of $\mathrm{CD}^{+}$and $\mathrm{CD} 8^{+} \mathrm{T}$ cells, including cTfh cells, in acutely infected patients and a strong correlation of T-cell activation with several hallmarks of humoral responses. Our longitudinal analysis additionally revealed residual activation of the T-cell pool and progressive expansion of cTfh, Th1 and Th1/17 CD4 ${ }^{+} T$ cells and subsets of memory $\mathrm{CD}^{+} \mathrm{T}$ cells during convalescence. These results suggest the continuous evolution of adaptive immunity to SARS-CoV-2 and are consistent with viral persistence in mucosal reservoirs or peripheral lymph nodes. ${ }^{18}$

In agreement with earlier reports, ${ }^{52}$ severe COVID-19 patients with increased inflammation also showed augmented T-cell activation and humoral responses during acute infection. This observation may be explained by the presence of higher viral loads or prolonged periods of active viral replication in severe patients. However, a pathogenic role of adaptive immunity cannot be completely ruled out.

The role of innate immune responses in COVID19 pathogenesis has been extensively described. ${ }^{41}$ SARS-CoV-2 infection induces delayed and dysregulated IFN responses, thereby impairing proper priming of adaptive immune responses. In concordance with recent literature, ${ }^{44,53}$ our data revealed a dramatic decrease in pDCs in acute infection that was marginally restored during convalescence. Although the depletion of circulating $\mathrm{pDCs}$ during acute infection could be suggestive of a targeted recruitment into virally infected tissues, their persistent lower frequency during convalescence argues in favor of a massive pDC apoptosis because of their activation through IFN signalling. ${ }^{54}$ Moreover, being $\mathrm{pDCs}$ the main source of type I IFN, their loss may be linked to the aberrant interferon responses displayed by severe COVID-19 patients. Indeed, our study indicated that $\mathrm{pDC}$ depletion contributed to the definition of distinct immune signatures that correlated with poor prognosis and inflammation.

Moreover, as reported by others, ${ }^{5,55}$ we found that acute SARS-CoV-2 infection markedly reduced HLA-DR expression on circulating myeloid cells and depleted non-conventional monocytes from circulation. Furthermore, our data revealed a negative correlation between HLA-DR expression and disease severity. Indeed, such decrease in HLA-DR expression has been recently associated with defective antigen presentation driven by an excessive release of IL-6. ${ }^{5}$ Finally, we found persistent changes in the circulating NK cell pool of patients infected with SARS-CoV-2. Our data are in line with previous reports suggesting a dysfunctional/exhausted phenotype of NK cells in COVID-19 patients as a consequence of hyperinflammation. ${ }^{56}$

In summary, our in-depth characterisation of SARS-CoV-2-specific B-cell responses revealed a previously unappreciated expansion of virusspecific naïve-like $B$ cells over time, perhaps through the continuous mobilisation of mature Bcell precursors to the periphery. Moreover, our results consolidated previous findings on the immune response dynamics occurring in COVID-19 patients, showing both transient and long-lasting changes associated with disease severity and development of immune memory.

\section{METHODS}

\section{Experimental model and subject details}

\section{Study cohort}

Blood samples were collected from COVID-19 hospitalised patients $(n=25)$ in acute phase of infection (COVT1) at the 
Hospital del Mar (Barcelona, Spain), with patient informed consent. Only patients with confirmed SARS-CoV-2 infection by reverse transcription-quantitative polymerase chain reaction (RT-qPCR) of nasopharyngeal swab were included. All COVT1 samples were collected within the first 14 days following symptom onset, being the median time from symptom onset to blood testing 11 days [8-14]. A follow-up blood sample was collected from 20 out of the 25 initial participants two months after first sample collection (COVT2), being the median time from symptom onset to COVT2 blood testing 70 days [59-84]. The median age of patients was 51 years. $52 \%$ were males. The median length of stay from hospitalisation to discharge was 16 days [5-90]. Clinical laboratory data were collected from the date closest to the first day of hospitalisation. Blood samples from agematched healthy donors $(n=21)$ were also collected. In addition, blood samples were obtained from 5 COVID-19 convalescent individuals 3 and 6 months after symptom onset to assess the persistency of humoral responses. All research subjects were pseudonymised by replacing directly identifiable variables with an ID immediately when collecting data. Patients ID were not known to anyone outside the research group. Demographic and clinical data of patients included in the study are summarised in Supplementary table 1 . All procedures followed were approved by the Ethical Committee for Clinical Investigation of the Institut Hospital del Mar d'Investigacions Mèdiques (Number 2020/9189/I).

\section{Sample collection and processing}

For all COVID-19 patients and healthy volunteers, sera were collected from whole blood in silica-treated tubes (BD Biosciences, Franklin Lakes, USA), heat-inactivated at $56^{\circ} \mathrm{C}$ for $1 \mathrm{~h}$ and stored at $-80^{\circ} \mathrm{C}$ prior to use. Peripheral blood mononuclear cells (PBMCs) were isolated from whole blood collected with EDTA anticoagulant via Ficoll-Paque Premium (Cytiva, Freiburg, Germany) following the manufacturer's instructions. PBMCs were counted using Turk solution, resuspended in foetal bovine serum (FBS; Gibco, Riverside, MA, USA) with $10 \%$ dimethyl sulphoxide (DMSO; Sigma-Aldrich, St. Louis, USA) and stored in liquid nitrogen prior to use.

\section{Production of recombinant SARS-CoV-2 proteins}

The pCAGGS RBD construct, encoding for the receptorbinding domain of the SARS-CoV-2 Spike protein (amino acids 319-541 of the Spike protein) along with the signal peptide plus a hexahistidine tag, was provided by $\mathrm{Dr}$ Krammer (Mount Sinai School of Medicine, NY USA). The pLVX-EF1alpha-nCoV2019-N-2xStrep-IRES-Puro construct, encoding for the full-length SARS-CoV-2 nucleocapsid protein (NP) fused to a double Strep-tag at the C-terminus, was a gift from Dr Krogan (University of California, San Francisco USA). Recombinant proteins were expressed inhouse in Expi293F human cells (Thermo Fisher, Waltham, MA, USA) by transfection of the cells with purified DNA and polyethylenimine (PEI). For secreted RBD proteins, cells were harvested 3 days post-transfection and RBDcontaining supernatants were collected by centrifugation at $20000 \mathrm{~g}$ for $15 \mathrm{~min}$. RBD proteins were purified in HiTrap $\mathrm{Ni}$
Columns in an automated fast protein liquid chromatography (FPLC; ÄKTA avant, Cytiva), concentrated through $10 \mathrm{kDa}$ Amicon centrifugal filter units (Merck Millipore, Darmstadt, Germany) and resuspended in PBS. For NP, cell lysates from transfected cells were centrifuged at $20000 \mathrm{~g}$ for $20 \mathrm{~min}$ and the supernatant was loaded into a 5-mL Strep-Tactin XT column. The eluted nucleocapsid was concentrated through a $10 \mathrm{kDa}$ Amicon centrifugal filter unit and purified with SEC (Sephadex 10/300) in PBS.

\section{Enzyme-linked immunosorbent assay (ELISA)}

ELISAs performed in this study were adapted from previously established protocols. ${ }^{45}$ 96-well half-area flatbottom high-bind microplates (Corning, New York, USA) were coated overnight at $4^{\circ} \mathrm{C}$ with each respective recombinant viral protein at $2 \mu \mathrm{g} \mathrm{mL}^{-1}$ in PBS $(30 \mu \mathrm{L}$ per well) or with PBS alone. Plates were washed with PBS $0.05 \%$ Tween-20 (PBS-T) and blocked with blocking buffer (PBS containing $1.5 \%$ bovine serum albumin, BSA) for $2 \mathrm{~h}$ at RT. Serum samples were serially diluted in PBS-T supplemented with $1 \%$ BSA and added to the viral protein- or PBS-coated plates for $2 \mathrm{~h}$ at RT. After washing, plates were incubated with horseradish peroxidase (HRP)-conjugated anti-human Ig secondary antibodies diluted in PBS-T supplemented with $1 \%$ BSA for $45 \mathrm{~min}$ at RT. Plates were washed 5 times with PBS-T and developed with TMB substrate reagent set (BD bioscience) with development reaction stopped with $1 \mathrm{M}$ $\mathrm{H}_{2} \mathrm{SO}_{4}$. Absorbance was measured at $450 \mathrm{~nm}$ on a microplate reader (Infinite 200 PRO, Tecan, Männedorf, Switzerland). To detect RBD-specific and NP-specific IgM, $\lg A$ and $\lg G$, goat HRP-conjugated anti-human $\lg A$ and $F$ $\left(a b^{\prime}\right) 2$ anti-human $\operatorname{lgG}$ and $\operatorname{lgM}$ (Southern Biotech, Birmingham, USA) were used at a 1:4000 dilution. To measure RBD and NP-specific IgG subclasses, HRP-conjugated mouse anti-human $\operatorname{lgG} 1, \lg G 2, \lg G 3$ and $\lg G 4$ (Southern Biotech) were used at a 1:3000 dilution. To detect SARSCoV-2-specific IgA1 and IgA2, HRP-conjugated mouse antihuman $\lg A 1$ or $\lg A 2$ (Southern Biotech) was used at a dilution of $1: 2000$ and $1: 4000$, respectively. To quantitate the level of each viral antigen-specific antibody class or subclasses, optical density (OD) values were calculated after subtraction of background (OD450 of serum dilutions on PBS-coated plates) and the area under the curve (AUC) derived from optical density measurements of six serial dilutions was determined using Prism 8 (GraphPad Software; San Diego, USA). AUC values below an established cut-off were replaced by the AUC value of the cut-off for plotting and calculation purposes. Negative threshold values were set using healthy control AUC levels plus 2 times the standard deviations of the mean.

The concentration of interleukin-7 (IL-7) was measured by a sandwich ELISA kit (PeproTech, London, UK) following the manufacturer's instructions on $50 \mu \mathrm{L}$ plasma samples. The levels of IL-7 were expressed as pg mL $\mathrm{mL}^{-1}$ of plasma.

\section{Spectral flow cytometry}

For spectral flow cytometry, frozen PBMCs were thawed and resuspended in $2 \mathrm{~mL}$ of LIVE/DEAD Fixable Yellow Dead Cell Stain Kit (Thermo Fisher), incubated for $30 \mathrm{~min}$ at RT and stained with two different fluorophore-conjugated 
antibody cocktails (Supplementary tables 2 and 4). For staining, a sequential approach was followed. Anti-CCR7 antibody was added first and incubated for $10 \mathrm{~min}$. Then, all other anti-chemokine receptor antibodies (CXCR3, CXCR4, CXCR5, CCR4 and CCR6 for MIX3, and CXCR3 and CXCR4 for MIX 1) were added to the corresponding tubes and incubated for $10 \mathrm{~min}$. After that, the remaining antibodies were added and incubated for $20 \mathrm{~min}$ (MIX 1) or $30 \mathrm{~min}$ (MIX 3). Stained cells resuspended in 4\% paraformaldehyde in PBS, and incubated for $12 \mathrm{~min}$ in ice. Fixed cells were then washed, resuspended in PBS and acquired using the Aurora spectral analyser (Cytek Biosciences, Fremont, CA, USA). Data were analysed using FlowJo V10.6.2 software (TreeStar Inc., Ashland, USA).

\section{Flow cytometric detection of SARS-CoV-2-RBD- specific B cells}

1.5 million frozen PBMCs were thawed, centrifuged and resuspended in a 1:20 000 PBS dilution of LIVE/DEAD Fixable Yellow Dead Cell Stain Kit (Thermo Fisher) for $30 \mathrm{~min}$ at RT to exclude dead cells. Cells were then washed with PBS and incubated with 13.2 pmol SARS-CoV-2 RBDHIS Biotinylated Recombinant Protein (Sino Biological Inc., Beijing, China) diluted in $50 \mu \mathrm{L} 1 \mathrm{X}$ PBS supplemented with $0.2 \% \mathrm{BSA}$ and $2 \mathrm{mM}$ EDTA for $30 \mathrm{~min}$ in ice. Cells were washed again and stained with the MIX 2 antibody cocktail (Supplementary table 3) plus 1.32 pmol Streptavidin Alexa Fluor 647 (Thermo Fisher) for $30 \mathrm{~min}$. Stained cells were washed, fixed with $4 \%$ paraformaldehyde in PBS for 12 min and acquired with LSR Fortessa (BD Biosciences). Data were further analysed with FlowJo V10.6.2 software.

Alternatively, 6.6 pmol SARS-CoV-2 RBD-HIS Biotinylated Recombinant Protein was incubated for $1 \mathrm{~h}$ in PBS with $0.94 \mathrm{pmol}$ Streptavidin Alexa Fluor 647 and $0.94 \mathrm{pmol}$ Streptavidin Alexa Fluor 488 (Thermo Fisher), separately. Meanwhile, 1.5 million frozen PBMCs were thawed, centrifuged and resuspended in $50 \mu \mathrm{L}$ PBS. Next, cells were incubated in the same staining tube with the labelled RBD probes for $20 \mathrm{~min}$ in ice. Cells were then washed and stained with the MIX 2 antibody cocktail for 10 min using anti-human IgA AmCyan instead of anti-human IgA FITC (Supplementary table 3) and DAPI fluorescent dye (SigmaAldrich). Stained cells were washed and resuspended in PBS $2 \%$ FBS and acquired on LSR Fortessa (BD Bioscience).

\section{Data analysis and visualisation}

t-Distributed stochastic neighbour embedding (tSNE) analyses were performed with FlowJo V10.6.2 software. tSNE analysis was performed using equal sampling from each FCS file, with 1000 iterations, a perplexity of 30, a Barnes-Hut gradient algorithm and exact KNN algorithm.

GraphPad Prism (version 8.0) and R (version 3.6.3; R Core Team (2019). R: A Language and Environment for Statistical Computing) were used to conduct statistical analyses. For each experiment, the type of statistical test, summary statistics and levels of significance were specified in the figures and corresponding legends. The correlation analysis was performed in R. We performed data imputation of the missing variables using predictive mean matching implemented in the mice package. ${ }^{57}$ Pairwise Spearman's rank correlations between 41 variables (including antibody titres measured by ELISA and immune parameters defined by high-dimensional flow cytometry; Supplementary data file 1) for COVT1 $(n=25)$, COVT2 $(n=20)$ and healthy controls $(n=16)$ were calculated and visualised as a correlogram using $\mathrm{R}$ package corrplot (Taiyun Wei and Viliam Simko (2017). R package 'corrplot': Visualization of a Correlation Matrix). Spearman's rank correlation coefficient ( $\rho$ ) was indicated by heat scale; significance was indicated by $* P<0.05, * * P<0.01$ and $* * * P<0.001$; FDR correction was performed using the Benjamini-Hochberg procedure at the FDR $<0.05$ significance threshold. Principal component analysis (PCA) was used to identify the most important features from 41 variables (including antibody titres and immune parameters; Supplementary data file 1) using COVT1 $(n=25)$, COVT2 $(n=20)$ and healthy controls $(n=16)$. The PCA was conducted using the 'prcomp' function in $R$ and visualised using the 'factoextra' package (Kassambara A, and Mundt F. factoextra: Extract and Visualize the Results of Multivariate Data Analyses, 2020).

\section{ACKNOWLEDGMENTS}

We acknowledge the patients and the Parc de Salut Mar MARBiobanc (PT17/0015/0011) integrated in the Spanish National Biobanks Network from ISCIII for their collaboration. MARBiobanc's work was supported by grants from Instituto de Salud Carlos III/FEDER (PT17/0015/0011) and the 'Xarxa de Bancs de tumors' sponsored by Pla Director d'Oncologia de Catalunya (XBTC). This study was supported by the COVID-19 call grant from Generalitat de Catalunya, Department of Health (to GM and LDCM), and grant Miguel Servet Research Program (to GM).

\section{CONFLICT OF INTEREST}

The authors declare that they have no competing financial interests.

\section{AUTHOR CONTRIBUTIONS}

Leire de Campos-Mata: Conceptualization; Data curation; Formal analysis; Investigation; Methodology; Resources; Visualization; Writing-original draft; Writing-review \& editing. Sonia Tejedor Vaquero: Conceptualization; Data curation; Formal analysis; Methodology; Resources; Visualization; Writing-review \& editing. Roser Tachó-Piñot: Investigation; Methodology; Writing-review \& editing. Janet Piñero: Data curation; Formal analysis; Investigation; Visualization. Emilie K Grasset: Data curation; Writingreview \& editing. Itziar Arrieta: Resources; Writing-review \& editing. Natalia Rodrigo Melero: Resources. Carlo Carolis: Resources. Juan P Horcajada: Investigation; Writing-review \& editing. Andrea Cerutti: Conceptualization; Investigation; Writing-original draft; Writing-review \& editing. Judit Villar-Garcia: Investigation; Project administration; Resources; Writing-review \& editing. Giuliana Magri: Conceptualization; Data curation; Formal analysis; Funding acquisition; Investigation; Methodology; Project administration; Resources; Supervision; Validation; 
Visualization; Writing-original draft; Writing-review \& editing.

\section{DATA AVAILABILITY STATEMENT}

All data are available in the main text or the supplementary materials. Further information and requests for resources and reagents should be directed to and will be fulfilled by the corresponding author, Giuliana Magri (gmagri@ imim.es).

\section{REFERENCES}

1. WHO Coronavirus Disease (COVID-19) Dashboard. Geneva, World Heal. Organ; 2020. https://covid19.who. int/ (accessed 12 August 2021).

2. Guan W, Ni Z, Hu Y et al. Clinical characteristics of coronavirus disease 2019 in China. N Engl J Med 2020; 382: 1708-1720.

3. Mehta P, McAuley DF, Brown M, Sanchez E, Tattersall RS, Manson JJ. COVID-19: consider cytokine storm syndromes and immunosuppression. Lancet 2020; 395: 1033-1034.

4. Tay MZ, Poh CM, Rénia L, MacAry PA, Ng LFP. The trinity of COVID-19: immunity, inflammation and intervention. Nat Rev Immunol 2020; 20: 363-374.

5. Giamarellos-Bourboulis EJ, Netea MG, Rovina N et al. Complex immune dysregulation in COVID-19 patients with severe respiratory failure. Cell Host Microbe 2020; 27: 992-1000.

6. Hadjadj J, Yatim N, Barnabei L et al. Impaired type I interferon activity and inflammatory responses in severe COVID-19 patients. Science 2020; 369: 718-724.

7. Mangalmurti $\mathrm{N}$, Hunter CA. Cytokine storms: understanding COVID-19. Immunity 2020; 53: 19-25.

8. Bastard P, Rosen LB, Zhang $Q$ et al. Autoantibodies against type I IFNs in patients with life-threatening COVID-19. Science 2020; 370: eabd4585.

9. Zuo Y, Estes SK, Ali RA et al. Prothrombotic autoantibodies in serum from patients hospitalized with COVID-19. Sci Transl Med 2020; 12: eabd3876.

10. Wang EY, Mao T, Klein J et al. Diverse functional autoantibodies in patients with COVID-19. Nature 2021; 595: 283-288.

11. Le Bert N, Tan AT, Kunasegaran $\mathrm{K}$ et al. SARS-CoV-2specific $T$ cell immunity in cases of COVID-19 and SARS, and uninfected controls. Nature 2020; 584: 457-462.

12. Mathew D, Giles JR, Baxter AE et al. Deep immune profiling of COVID-19 patients reveals distinct immunotypes with therapeutic implications. Science 2020; 369: eabc8511.

13. Peng $Y$, Mentzer AJ, Liu $G$ et al. Broad and strong memory $\mathrm{CD}^{+}$and $\mathrm{CD}^{+} \mathrm{T}$ cells induced by SARS-CoV-2 in UK convalescent individuals following COVID-19. Nat Immunol 2020; 21: 1336-1345.

14. Dan JM, Mateus J, Kato $Y$ et al. Immunological memory to SARS-CoV-2 assessed for up to 8 months after infection. Science 2021; 371: eabf4063.

15. Wajnberg A, Amanat F, Firpo $A$ et al. Robust neutralizing antibodies to SARS-CoV-2 infection persist for months. Science 2020; 370: 1227-1230.
16. Rodda LB, Netland J, Shehata L et al. Functional SARSCoV-2-specific immune memory persists after mild COVID-19. Cell 2021; 184: 169-183.

17. Hartley GE, Edwards ESJ, Aui PM et al. Rapid generation of durable B cell memory to SARS-CoV-2 spike and nucleocapsid proteins in COVID-19 and convalescence. Sci Immunol 2020; 5: eabf8891.

18. Gaebler C, Wang Z, Lorenzi JCC et al. Evolution of antibody immunity to SARS-CoV-2. Nature 2021; 591: 639-644.

19. Sokal A, Chappert $P$, Barba-Spaeth $G$ et al. Maturation and persistence of the anti-SARS-CoV-2 memory B cell response. Cell 2021; 184: 1201-1213.

20. Kreer $C$, Zehner $M$, Weber $T$ et al. Longitudinal isolation of potent near-germline SARS-CoV-2neutralizing antibodies from COVID-19 patients. Cell 2020; 182: 1663-1673.

21. Kim SI, Noh J, Kim $S$ et al. Stereotypic neutralizing $V_{H}$ antibodies against SARS-CoV-2 spike protein receptor binding domain in patients with COVID-19 and healthy individuals. Sci Transl Med 2021; 13: eabd6990.

22. Robbiani DF, Gaebler C, Muecksch F et al. Convergent antibody responses to SARS-CoV-2 in convalescent individuals. Nature 2020; 584: 437-442.

23. Barnes CO, West AP, Huey-Tubman KE et al. Structures of human antibodies bound to SARS-CoV-2 spike reveal common epitopes and recurrent features of antibodies. Cell 2020; 182: 828-842.

24. Seydoux E, Homad LJ, Maccamy AJ, Pancera M, Mcguire AT, Stamatatos L. Analysis of a SARS-CoV-2-infected individual reveals development of potent neutralizing antibodies with limited somatic mutation. Immunity 2020; 53: 98-105.

25. Schultheiß C, Paschold L, Simnica D et al. NextGeneration Sequencing of $\mathrm{T}$ and $\mathrm{B}$ Cell Receptor Repertoires from COVID-19 Patients Showed Signatures Associated with Severity of Disease. Immunity 2020; 53: 442-455.

26. Feldman J, Bals J, \& Altomare CG et al. Naive human B cells engage the receptor binding domain of SARSCoV-2, variants of concern, and related sarbecoviruses. bioRxiv 2021. https://doi.org/10.1101/2021.02.02.429458.

27. Sterlin D, Mathian A, Miyara $M$ et al. IgA dominates the early neutralizing antibody response to SARS-CoV-2. Sci Transl Med 2020; 13: eabd2223.

28. Woodruff MC, Ramonell RP, Nguyen DC et al. Extrafollicular B cell responses correlate with neutralizing antibodies and morbidity in COVID-19. Nat Immunol 2020; 21: 1506-1516.

29. Muehlinghaus G, Cigliano L, Huehn S et al. Regulation of CXCR3 and CXCR4 expression during terminal differentiation of memory $B$ cells into plasma cells. Blood 2005; 105: 3965-3971.

30. Cain D, Kondo M, Chen H, Kelsoe G. Effects of acute and chronic inflammation on B-cell development and differentiation. J Invest Dermatol 2009; 129: 266-277.

31. Groom JR, Luster AD. CXCR3 ligands: redundant, collaborative and antagonistic functions. Immunol Cell Biol 2011; 89: 207-215.

32. Sanz I, Wei C, Jenks SA et al. Challenges and opportunities for consistent classification of human B cell and plasma cell populations. Front Immunol 2019; 10: 2458 . 
33. Ceredig R, Rolink AG. The key role of IL-7 in lymphopoiesis. Semin Immunol 2012; 24: 159-164.

34. Chailyan A, Marcatili P, Cirillo D, Tramontano A. Structural repertoire of immunoglobulin $\lambda$ light chains. Proteins 2011; 79: 1513-1524.

35. Chen Z, John Wherry E. T cell responses in patients with COVID-19. Nat Rev Immunol 2020; 20: 529-536.

36. Wilkinson TM, Li CKF, Chui CSC et al. Preexisting influenza-specific $\mathrm{CD}^{+}{ }^{+} \mathrm{T}$ cells correlate with disease protection against influenza challenge in humans. Nat Med 2012; 18: 274-280.

37. Miller JD, van der Most RG, Akondy RS et al. Human effector and memory $\mathrm{CD}^{+} \mathrm{T}$ cell responses to smallpox and yellow fever vaccines. Immunity 2008; 28: 710-722.

38. Crotty S. T follicular helper cell biology: a decade of discovery and diseases. Immunity 2019; 50: 1132-1148.

39. Morita R, Schmitt N, Bentebibel SE et al. Human Blood $\mathrm{CXCR5}^{+} \mathrm{CD}^{+}{ }^{+} \mathrm{T}$ Cells Are Counterparts of $\mathrm{T}$ Follicular Cells and Contain Specific Subsets that Differentially Support Antibody Secretion. Immunity 2011; 34: 108121.

40. Vella LA, Buggert M, Manne S et al. T follicular helper cells in human efferent lymph retain lymphoid characteristics. J Clin Invest 2019; 129: 3185-3200.

41. Schultze JL, Aschenbrenner AC. COVID-19 and the human innate immune system. Cell 2021; 184: 16711692.

42. Narasimhan PB, Marcovecchio $P$, Hamers AAJ, Hedrick CC. Nonclassical monocytes in health and disease. Ann Rev Immunol 2019; 37: 439-456.

43. Sánchez-Cerrillo I, Landete P, Aldave B et al. COVID-19 severity associates with pulmonary redistribution of $\mathrm{CD}_{1 \mathrm{C}^{+}} \mathrm{DCs}$ and inflammatory transitional and nonclassical monocytes. J Clin Invest 2020; 130: 62906300.

44. Zhou R, To KKW, Wong YC et al. Acute SARS-CoV-2 infection impairs dendritic cell and $\mathrm{T}$ cell responses. Immunity 2020; 53: 864-877.

45. de Campos Mata L, Piñero J, Vaquero ST et al. SARSCoV-2-specific antibody profiles distinguish patients with moderate from severe COVID-19. medRxiv 2020; https://doi.org/10.1101/2020.12.18.20248461.

46. Pasquier $B$, Launay $P$, Kanamaru $Y$ et al. Identification of $\mathrm{FcaRI}$ as an inhibitory receptor that controls inflammation: dual role of FcR $\gamma$ ITAM. Immunity 2005; 22: $31-42$.

47. Cervia C, Nilsson J, Zurbuchen $Y$ et al. Systemic and mucosal antibody responses specific to SARS-CoV-2 during mild versus severe COVID-19. J Allergy Clin Immunol 2021; 147: 545-557.
48. Ferreira-Gomes $M$, Kruglov A, Durek $P$ et al. SARS-CoV2 in severe COVID-19 induces a TGF- $\beta$-dominated chronic immune response that does not target itself. Nat Commun 2021; 12: 1961.

49. Lenti MV, Aronico N, Pellegrino I et al. Depletion of circulating IgM memory $B$ cells predicts unfavourable outcome in COVID-19. Sci Rep 2020; 10: 20836.

50. Wardemann H, Yurasov S, Schaefer A, Young JW, Meffre E, Nussenzweig MC. Predominant autoantibody production by early human B cell precursors. Science 2003; 301: 1374-1377.

51. Weiskopf D, Schmitz KS, Raadsen MP et al. Phenotype and kinetics of SARS-CoV-2-specific T cells in COVID-19 patients with acute respiratory distress syndrome. Sci Immunol 2020; 5: eabd2071.

52. Brodin P. Immune determinants of COVID-19 disease presentation and severity. Nat Med 2021; 27: 28-33.

53. Kuri-Cervantes L, Pampena MB, Meng $\mathrm{W}$ et al. Comprehensive mapping of immune perturbations associated with severe COVID-19. Sci Immunol 2020; 5: eabd7114.

54. Swiecki M, Wang Y, Vermi W, Gilfillan S, Schreiber RD, Colonna M. Type I interferon negatively controls plasmacytoid dendritic cell numbers in vivo. J Exp Med 2011; 208: 2367-2374.

55. Schulte-Schrepping J, Reusch N, Paclik D et al. Severe COVID-19 is marked by a dysregulated myeloid cell compartment. Cell 2020; 182: 1419-1440.

56. van Eeden C, Khan L, Osman MS, Tervaert JWC. Natural killer cell dysfunction and its role in COVID-19. Int J Mol Sci 2020; 21: 1-17.

57. van Buuren S, Groothuis-Oudshoorn K. mice: multivariate imputation by chained equations in R. $J$ Stat Softw 2011; 45: 1-67.

\section{Supporting Information}

Additional supporting information may be found online in the Supporting Information section at the end of the article.

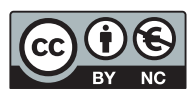

This is an open access article under the terms of the Creative Commons Attribution NonCommercial License, which permits use, distribution and reproduction in any medium, provided the original work is properly cited and is not used for commercial purposes. 